
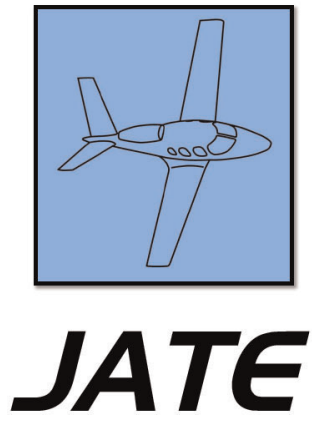

Journal of Aviation Technology and Engineering 10:2 (2021) 16-33

\title{
Characteristics of Unmanned Aircraft System (UAS) Sightings and Airport Safety
}

\author{
Cheng Wang ${ }^{1}$ and Sarah M. Hubbard ${ }^{2}$ \\ ${ }^{1}$ Minnesota State University, Mankato \\ ${ }^{2}$ Purdue University
}

\begin{abstract}
This paper presents the characteristics of unmanned aircraft system (UAS) sightings and discusses these characteristics in the context of airport safety using airport operational data. An unmanned aircraft in the vicinity of a commercial airport may be a potential threat to aircraft operations, and may result in operational and economic impacts if it causes an airport delay or shutdown. To ensure a record of UAS activity, the Federal Aviation Administration collects and publishes a UAS Sightings Report. This study analyzed UAS sightings and found that they vary by time of year and time of day, with more sightings in the summer and during the daytime. While all kinds of aircraft may be affected, pilots of general aviation aircraft report more UAS sightings, although overall only 3.3 percent of sightings required the pilot to take evasive action. Only 9.8 percent of UAS sightings occurred at or below 400 feet and 57 percent occurred within five miles of an airport, and sightings are more likely to be reported close to large and medium hub airports. States with a large population (such as California and Florida) and airports in big cities have more UAS sightings. The airports with the most UAS sightings are LaGuardia (LGA), Los Angeles (LAX), John F. Kennedy (JFK), and O’Hare (ORD).
\end{abstract}

Keywords: unmanned aircraft systems sighting, airport safety, drone, UAS, sUAS

\section{Introduction}

The prevalence of unmanned aircraft systems (UASs) has grown dramatically in recent years due to advances in UAS technology, reduced UAS costs, and Part 107, the regulatory framework for the operation of small UASs in the USA. With increasing UASs, an important consideration is maintaining safety for airport operations and manned aircraft. Therefore, the purpose of this study is to better understand the reported UAS activity and how this relates to airport operations. This paper first discusses the characteristics of UAS sightings based on reports from September 2016 to August 2019 in the Federal Aviation Administration's (FAA, 2020a) UAS sighting database. This paper then discusses the UAS sighting data in the context of airport operation data. A better understanding of the UAS sighting data is valuable to increase understanding of the potential threat of UASs, increase awareness of the UAS sighting database, and as a first step toward protecting the airspace around airports from operational disruptions caused by UAS sightings. 


\section{Background}

The presence of UASs may affect airport operations and safety. A UAS sighting may result in an airport delay or shutdown, which disrupts airport operations and can lead to significant economic losses. A UAS ingested into a jet engine can cause engine failure (D'Souza et al., 2017; Kota et al., 2020; Lyons \& D'Souza, 2019; Olivares et al., 2017a, 2017b; Yu et al., 2021), and cause an incident or accident. UAS sightings at major airports illustrate the potential impacts and are described below.

\section{UAS Sightings at Dubai International Airport}

Dubai International Airport has been affected by unauthorized UAS activities multiple times in the past several years.

- In January 2015, air traffic was halted when UASs were flown into the flight path, suspending air traffic from 3 p.m. to 3:55 p.m. and diverting some inbound flights to Dubai's Al Maktoum International Airport (Mutzabaugh, 2015).

- In June 2016, the airport was again closed to aircraft from 11:36 a.m. to 12:45 p.m. due to reports of UAS activity, and 21 flights were diverted to three nearby airports (Remeithi, 2016).

- In September 2016, the airspace around the airport was closed from 8:08 a.m. to 8:35 a.m. following another UAS sighting, resulting in delays to 90 flights (Debusmann, 2016; Pennington, 2016).

- In October 2016, Dubai and Sharjah International Airports were both closed for more than an hour each due to a UAS in the airspace of the two airports (Pennington, 2016). The airspace around Dubai was closed from 7:25 p.m. to 8:45 p.m., forcing the diversion of 22 inbound flights. The closure at Sharjah began around 8 p.m., and flights were cleared to take off again at 9 p.m., which affected eight flights.

- In February 2019, a suspected UAS sighting briefly disrupted departure flights from the airport, which resulted in the closure of the airspace around the airport from 10:13 a.m. to 10:45 a.m. It was estimated that departures were delayed by up to an hour due to the shutdown (Nasseri, 2019; Porter, 2019). An official later reported that the incident was caused by an individual operating a UAS in a nearby desert (Dobush, 2019).

Although disruptions to air traffic were relatively brief, even short delays can cause considerable problems at Dubai International Airport, as the third busiest airport in the world. According to the Emirates Authority for Standardization and Metrology, airports in the United Arab Emirates suffer direct financial losses of $\$ 95,368$ (AED350,000) for each minute that Dubai International Airport is shut down due to UAS activity (Deulgaonkar, 2017). The total losses due to these five events are estimated to be $\$ 25.46$ million.

\section{UAS Sighting at Gatwick Airport}

Between December 19 and 21 in 2018, a series of UAS sightings at Gatwick Airport disrupted about 1,000 flights and resulted in a 36-hour shutdown of England's second busiest airport (Yeginsu, 2018). The shutdown was initiated after two UASs were spotted flying over the perimeter fence and into the airside of the airport ("Gatwick airport," 2018). According to reports from the airport, over 120,000 passengers were affected on December 19 and 20, and 160 of 837 scheduled flights on December 21 were cancelled (Topham, 2018). Due to the displacement of crews and aircraft that resulted from the above disruptions, there were also delays to some scheduled flights on December 22. In addition to widespread flight disruptions, the UAS sightings at Gatwick Airport resulted in considerable economic losses for airlines and the airport. Losses for aviation businesses were estimated to be between $£ 50$ million and $£ 70$ million (Calder, 2019). Moreover, the incident revealed how the UK airport system could be affected by disruption due to UASs (Britton \& Clarke, 2018).

\section{UAS Sighting at Newark Liberty International Airport}

On the evening of January 22, 2019, airline pilots reported a UAS in their approach path to Newark Liberty International Airport (EWR), which led the FAA to stop air traffic for 21 minutes (Shepardson, 2019; Silk, 2019). The agency received two reports of UASs operating near the airport from two airline pilots at 4:44 p.m. (Aratani, 2019; Cohen, 2019). One of the pilots said he saw what he believed to be a UAS at about 3,500 feet above Teterboro Airport. An air traffic controller who watched over airspace around EWR also spotted two UASs flying close to a plane ("FAA investigating drone scare," 2019). Based on the reports, inbound flights to EWR were held in the air and takeoffs were momentarily stopped as a precaution (Dow, 2019). In total, 43 inbound flights were held in the air, 10 were diverted to land at other airports, and another 170 flights bound for EWR were briefly delayed on the ground before taking off from other airports. The EWR stoppage marked the first and only shutdown at a major U.S. airport due to unauthorized UAS activities.

\section{Previous Studies of UAS Sightings}

A literature search using "UAS," "UAV," or "drone*", in the title resulted in thousands of peer-reviewed journal articles about UASs since 2010. However, a review of titles

\footnotetext{
${ }^{1}$ The asterisk $(*)$ was used in the literature search to broaden the search and to find words that start with "drone."
} 
suggests most of the research focuses on the applications of UASs, and there have been very few studies of UAS sightings, although the safe integration of UASs into the National Airspace System has been a significant challenge and is a top priority of the FAA (2018a). Previous studies on UAS sightings include research by Gettinger and Michel (2015), the Academy of Model Aeronautics (AMA, 2016, 2017), and the Unmanned Aircraft Safety Team (UAST, 2017).

The UAST (2017) selected specific criteria and applied them to UAS sighting reports to elicit informative data points. This methodology is used by researchers to review and analyze UAS sightings in this study. The six criteria selected by the UAST are: if the UAS sighting was observed by a pilot; what the UAS altitude was; how far the UAS was from the manned aircraft; if the pilot described the UAS sighting as a near miss; if the pilot took evasive action; if the UAS sighting occurred within five miles of an airport or during the takeoff or landing phase of the flight. Table 1 shows the most important findings from these studies.

\section{Data Source and Data Analysis}

UAS sighting reports analyzed in this study were obtained from the FAA's (2020a) UAS sighting database. As of July 1, 2020, the FAA released 9,968 reports for UAS sightings between November 2014 and March 2020. This study examined 6,544 UAS sightings occurring during the three-year period September 2016 to August 2019; the beginning of this time period reflects the time when Part 107 officially went into effect on August 29, 2016. There may be some concerns with the FAA UAS database (e.g., whether it is comprehensive and whether each entry has been adequately validated); however, this database is the best information currently available. The FAA is the agency responsible for collection, compilation, and publication of these data, and is also responsible for aviation in the USA. The FAA is also a global leader in aviation and safety. The airport operations data for this study were obtained from the airport operations section of the FAA's (2020b) Air Traffic Activity Data System (ATADS), which contains official National Airspace System air traffic operations data.

UAS sighting reports generally provide information about the event date, time, city, and state and a narrative of the event. For each UAS sighting, the narrative was reviewed to identify the following information:

- UAS altitude

- The distance from UAS sighting location to the nearby airport

- Nearby airport

- Whether a mandatory occurrence report (MOR) was filed

- Relevant law enforcement department(s) that was notified of the UAS sighting

- The source of the UAS sighting report

- The model of manned aircraft (if involved)

- The position of UAS relative to manned aircraft

- The distance between UAS and manned aircraft

- Whether evasive action was taken by the pilot(s) of the manned aircraft

This research used a similar method to the UAST (2017) publication to analyze UAS sighting reports. Researchers reviewed UAS sighting reports to extract information about 10 selected criteria, presented in Table 2, which shows the methodology for analysis of the narrative in UAS sighting reports. This methodology provides reliable and potentially actionable insights to enhance veracity and informative nature of UAS sighting reports.

Table 1

Findings of UAS sightings from previous studies.

\begin{tabular}{|c|c|c|}
\hline Author (year) & $\begin{array}{l}\text { Number of UAS sightings } \\
\text { analyzed (time) }\end{array}$ & Findings of UAS sightings \\
\hline $\begin{array}{l}\text { Gettinger and } \\
\quad \text { Michel (2015) }\end{array}$ & $\begin{array}{l}921 \text { (Dec. 17, } 2013 \text { to Sep. 12, } \\
\text { 2015) }\end{array}$ & $\begin{array}{l}\text { - UAS sightings are most likely to occur during daytime. } \\
\text { - Over half of involved manned aircraft are general aviation aircraft. } \\
\text { - UAS sightings beyond five miles of an airport occurred at much higher altitudes than } \\
\text { UAS sightings within five miles of an airport in general. } \\
\text { - } 90 \% \text { of UAS sightings occurred above the FAA's } 400 \text {-foot ceiling for UASs. } \\
\text { - } 60 \% \text { of UAS sightings occurred within five miles from the reported airport. } \\
\text { - } 25 \% \text { of reports indicated the UAS-to-aircraft proximity was less than } 500 \text { feet. } \\
\text { - The top four cities for UAS sightings are New York, Los Angeles, Miami, and Chicago. }\end{array}$ \\
\hline AMA $(2016,2017)$ & $\begin{array}{l}582 \text { (Aug. } 21,2015 \text { to Jan. } \\
31,2016 \text { ) and } 1,270 \text { (Feb. } 1 \text {, } \\
2016 \text { to Sep. } 30,2016 \text { ) }\end{array}$ & $\begin{array}{l}\text { - } 93 \% \text { of UAS sightings occurred above the FAA's } 400 \text {-foot ceiling for UASs. } \\
\text { - } 3 \% \text { of cases were reported as near misses. } \\
\text { notification was unknown. }\end{array}$ \\
\hline UAST (2017) & 3,417 (Aug. 2015 to Mar. 2017) & $\begin{array}{l}\text { - } 70 \% \text { of UAS sightings occurred above the FAA's } 400 \text {-foot ceiling for UASs. } \\
\text { - Pilots took evasive action to avoid UASs in } 3.3 \% \text { of cases. } \\
\text { - } 16 \% \text { of reports indicated UAS-to-aircraft proximity was less than } 500 \text { feet. }\end{array}$ \\
\hline
\end{tabular}


Table 2

Identification and analysis of narrative in UAS sighting reports.

\begin{tabular}{|c|c|c|}
\hline Goal & Format & Methodology \\
\hline $\begin{array}{l}\text { To determine the UAS altitude } \\
\text { in feet above ground level. }\end{array}$ & $\begin{array}{l}\text { Numeric with no special charac- } \\
\text { ters or "unknown." }\end{array}$ & $\begin{array}{l}\text { No assumptions are made. If the report states, "drone passed above aircraft," } \\
\text { it is listed as unknown. }\end{array}$ \\
\hline $\begin{array}{l}\text { To determine the distance } \\
\text { between the location of } \\
\text { UAS sighting and the } \\
\text { airport in nautical miles. }\end{array}$ & $\begin{array}{l}\text { Numeric with no special charac- } \\
\text { ters or "unknown." }\end{array}$ & $\begin{array}{l}\text { No assumptions are made. If the report states, "EASTBOUND OVER } \\
\text { REDWOOD ROAD EAST OF SALT LAKE CITY ARPT," it is listed as } \\
\text { unknown. }\end{array}$ \\
\hline $\begin{array}{l}\text { To determine the airport that is } \\
\text { close to the location of UAS } \\
\text { sighting. }\end{array}$ & $\begin{array}{l}\text { In text, FAA's airport code } \\
\text { or "unknown." }\end{array}$ & $\begin{array}{l}\text { Narratives including specific airport that was close to the location of the UAS } \\
\text { sighting. Exemplary statement: " } 2 \text { NE SLC." }\end{array}$ \\
\hline $\begin{array}{l}\text { To determine whether a MOR } \\
\text { was filed. }\end{array}$ & "Yes" or "no." & The narrative indicates that a MOR was filed. \\
\hline $\begin{array}{l}\text { To determine whether law } \\
\text { enforcement department(s) } \\
\text { was notified of the UAS } \\
\text { sighting. }\end{array}$ & "Yes," "no" or "unknown." & $\begin{array}{l}\text { Narratives including specific department(s) that was notified of the UAS } \\
\text { sighting are classified as "yes." A report that states, "LEO } \\
\text { NOTIFICATION NOT REPORTED," is listed in "no." An example of } \\
\text { "unknown": "LEO NOTIFICATION UNKN." }\end{array}$ \\
\hline $\begin{array}{l}\text { To determine the source of the } \\
\text { UAS sighting. }\end{array}$ & $\begin{array}{l}\text { In text, "airport,” “ATC," } \\
\text { "citizen," "LEO,” } \\
\text { "military," “passenger," } \\
\text { "pilot," "other," or } \\
\text { "unknown." }\end{array}$ & $\begin{array}{l}\text { Exemplary statements: "U.S. PARK POLICE REPORTED SEEING A UAS," } \\
\text { and "A PASSENGER SIGHTED A UAS." }\end{array}$ \\
\hline $\begin{array}{l}\text { To determine the model of } \\
\text { manned aircraft involved in } \\
\text { the UAS sighting. }\end{array}$ & $\begin{array}{l}\text { In text, "commercial," "GA," } \\
\text { "helicopter," "military," "no } \\
\text { aircraft involved," or } \\
\text { "unknown." }\end{array}$ & $\begin{array}{l}\text { The type of manned aircraft involved in the UAS sighting is stated in the } \\
\text { narrative. }\end{array}$ \\
\hline $\begin{array}{l}\text { To determine whether pilot(s) } \\
\text { took evasive action to avoid } \\
\text { UAS. }\end{array}$ & "Yes" or "no." & $\begin{array}{l}\text { Exemplary statements: "EVASIVE ACTION TAKEN," "DESCEND TO } \\
\text { AVOID," or "BANKED LEFT." UAS sightings that required pilots to } \\
\text { "delay departure" or "slow down rate of climb" are also included. }\end{array}$ \\
\hline $\begin{array}{l}\text { To determine the distance } \\
\text { between UAS and manned } \\
\text { aircraft in feet. }\end{array}$ & $\begin{array}{l}\text { Numeric with no special } \\
\text { characters or "unknown." }\end{array}$ & $\begin{array}{l}\text { No assumptions are made. If the report states, "OFF LEFT SIDE } 300 \text { BELOW } \\
\text { AFCT," it is listed as unknown. }\end{array}$ \\
\hline $\begin{array}{l}\text { To determine the position of } \\
\text { UAS relative to manned } \\
\text { aircraft. }\end{array}$ & $\begin{array}{l}\text { In text, "above," "below," } \\
\text { "left," "right," "front," } \\
\text { "behind," or "unknown." }\end{array}$ & $\begin{array}{l}\text { Exemplary statements: "OBSERVED A BLACK UAS OFF HIS RIGHT } \\
\text { SIDE." }\end{array}$ \\
\hline
\end{tabular}

\section{Results}

This study analyzed 6,544 UAS sighting reports from 2016 to 2019, approximately 65 percent of the UAS sightings in the database since its inception on November 1, 2014, through March 31, 2020. The number of UAS sightings increased substantially between 2015 and 2018, as shown in Figure 1.

UAS sightings generally vary by time of year and time of day. Figure 2 shows the distribution of UAS sightings by month and by time of day. The most UAS sightings are reported in June; UAS sightings taper off in the fall, are the lowest in the winter, and begin to increase again in the spring. The top three months for UAS sighting reports are June, July, and May, and 45.3 percent occur between May and August. This distribution is likely due to increased UAS flights in the summer months, and increased general aviation (GA) traffic in the summer months (Mathew et al., 2017). The majority of UAS sightings occur during the daytime, with 76.9 percent between 11 a.m. and 6 p.m. local time. This is consistent with Part 107 during the study period (the FAA subsequently released the rule of
Operation of Small Unmanned Aircraft Systems Over People on January 15, 2021) which does not allow UAS operations from dusk to dawn (although the FAA does grant waivers). This also reflects trends in both commercial and GA flights; most commercial flights are between 7 a.m. and midnight; GA flights are most common during daylight hours.

The timing of manned flights is relevant for UAS sightings, since 93.5 percent of UAS sightings are reported by pilots, as shown in Figure 3. This is not surprising, because pilots are accustomed to working with Flight Standards District Office (FSDO), the agency that manages UAS sighting reports in the FAA's UAS Sighting Reports database. Pilots are most likely to see UASs, since they are in the air and actively observe the surroundings out of cockpit windows. Concerned citizens, airport officers, law enforcement officers, passengers, air traffic controllers, and others also report UAS sightings, but collectively represent only 6.5 percent of the UAS sighting reports submitted. Anecdotal evidence based on researchers' conversations with airport managers and airport operations personnel (details of individual conversations are protected by the 


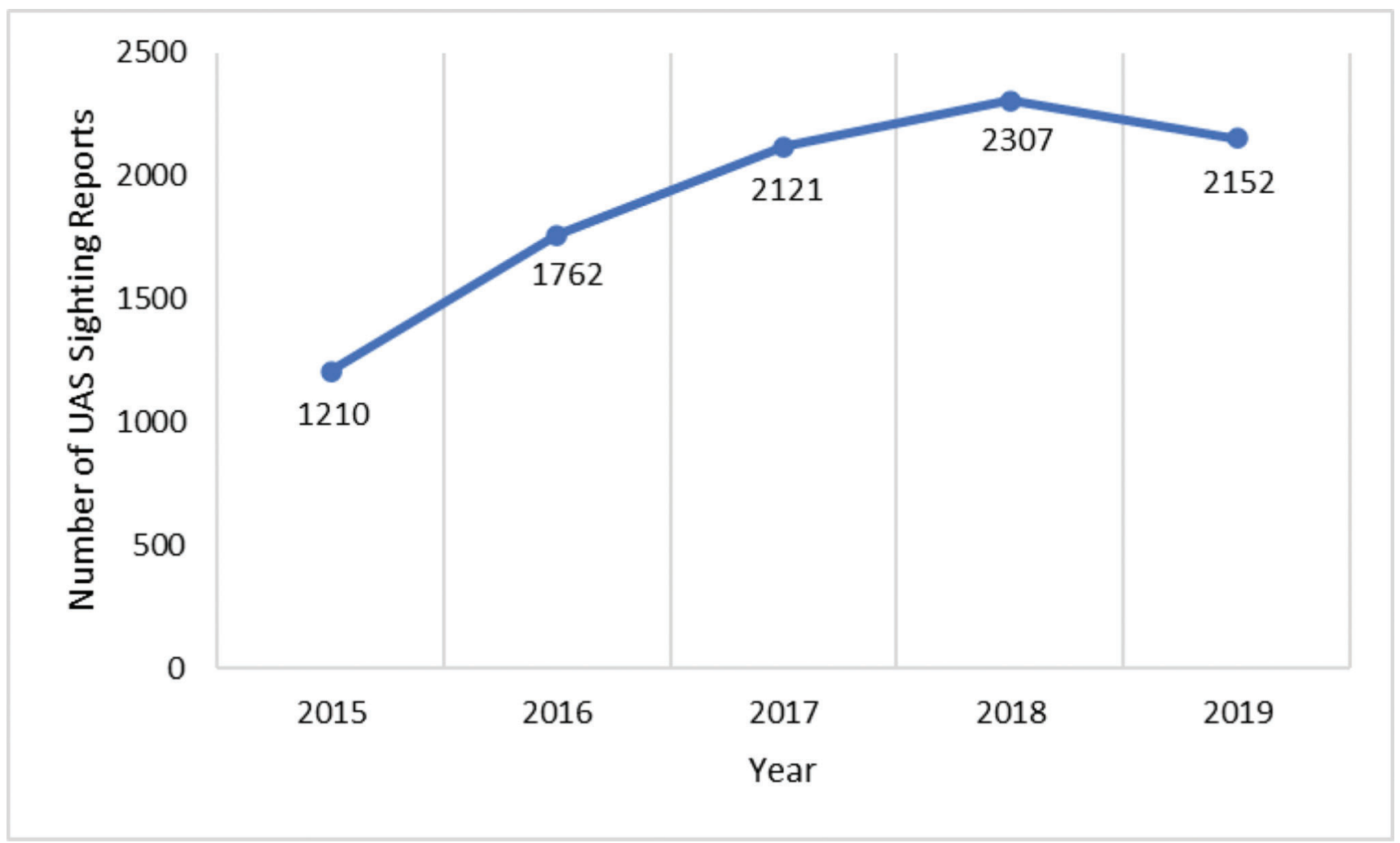

Figure 1. UAS sighting distribution by year, from 2015 to 2019 .

protocol of the Institutional Review Board) suggests that there is a general lack of awareness about the UAS sighting database in the airport community, including both the existence of the database and how to submit a UAS sighting report.

All kinds of aircraft may be affected by UASs, and this is reflected by the fact that pilots of a wide variety of aircraft have filed UAS sighting reports. Pilots of GA aircraft (such as a Cessna 172) and business jets (such as a Hawker 400) report the most UAS sightings, representing 43.3 percent of the reports, as shown in Figure 4(a). Pilots of large commercial aircraft (such as an A320) also report UAS sightings, and account for 37.6 percent of the reports. This suggests that commercial flight operations may be affected by UAS sightings, which may result in flight delays, diversions, cancelations, closure of runways, or even airport closure.

The high number of UAS sighting reports by GA aircraft is more striking when the operational mix is considered. According to the data from the FAA's (2020b) ATADS, GA accounts for only 16 percent of operations as shown in Figure 4(b), but comprises 43.3 percent of UAS sightings. This may be due to the lower altitudes of GA flights and may suggest that GA pilots warrant additional outreach efforts regarding UAS sighting reporting. In contrast, commercial operations account for 61.2 percent of all operations, although only 37.6 percent of UAS sightings involve commercial aircraft. This may be due to the fact that most of commercial flights fly above the altitude of UASs, and certainly above the altitude of UASs operating under Part 107, which mandates a maximum height of 400 feet.

In some cases, it is appropriate to report a UAS sighting to law enforcement for investigation, since local law enforcement is often in a better position to deter, detect, investigate, and pursue enforcement actions to stop unauthorized UAS operations (FAA, 2016). Figure 5 shows that in 73.8 percent of UAS sightings, law enforcement (e.g., airport police, local police, county sheriff, or state police) is notified or follow-up actions are taken by relevant departments. In a quarter of UAS sighting reports, it is unknown whether there is any report to law enforcement (15.8 percent of UAS sightings) or it is not reported to law enforcement (10.4 percent of UAS sightings). Although enforcement agencies are notified the majority of the time, sometimes it can be difficult to enforce UAS regulations and not all law enforcement has the resources or capabilities to deal with UAS sightings. Often the operator of the UAS cannot be found, which makes enforcement of unauthorized or illegal UAS operations impossible.

Reported UAS sightings may also result in a MOR filed by air traffic controllers. A MOR is mandatorily required for an occurrence that involves air traffic services (FAA, 2020c). A MOR is filed when a pilot reports or air traffic control (ATC) becomes aware of unauthorized UAS activity or authorized UAS activity that is conducted in an unsafe or hazardous manner. While all MORs are filed by 


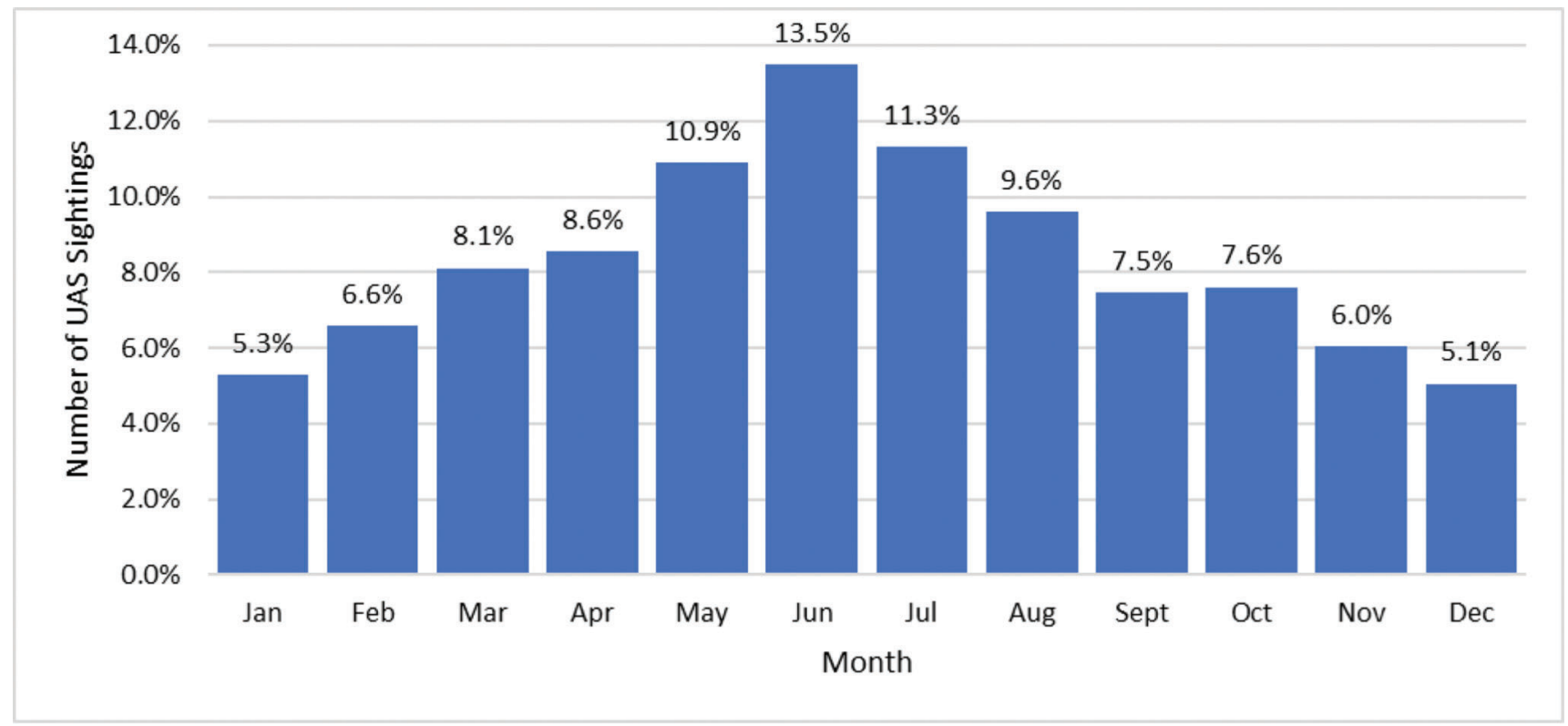

(a)

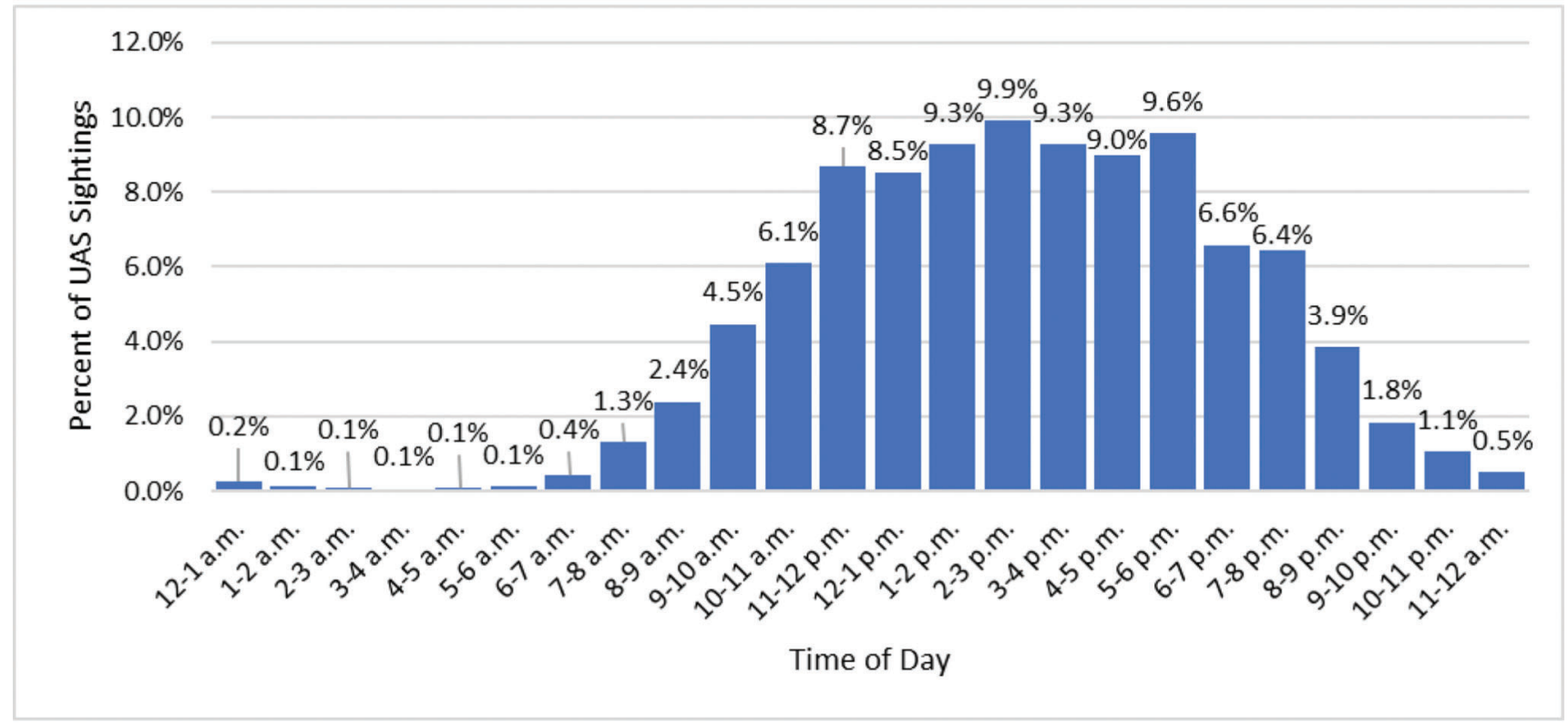

(b)

Figure 2. UAS sighting distribution: (a) by month; (b) by time of day (local time) (representing all 6,544 UAS sighting reports).

air traffic personnel, an incident resulting in a MOR alert can be reported by air traffic controllers, aircraft operators, aircraft owners, front line managers, or other parties. It appears that MORs are filed for 86.2 percent of UAS sightings. As shown in Figure 6, the UAS sighting database reports that a MOR is filed over 90 percent of the time when the UAS sighting is reported by a passenger or ATC, 87 percent of the time when the UAS sighting is reported by a pilot, over 70 percent of the time when the UAS is sighted by an airport officer or a citizen, and 40 percent of the time when the UAS sighting is reported by the military.
The UAS Sighting Reports database plays an important role in capturing UAS sighting data, because about 15 percent of the reports in the database are not reported to the MOR system.

Figure 7 shows the reported position of UASs relative to manned aircraft. For the 58 percent of the UAS sighting reports that include position: most reports indicate that the UAS is below the aircraft (39.7 percent), the least reported position of the UAS is behind the aircraft (0.7 percent), and UASs are equally likely to be reported to either side (20.4 percent on the port side and 20.7 percent on the starboard 


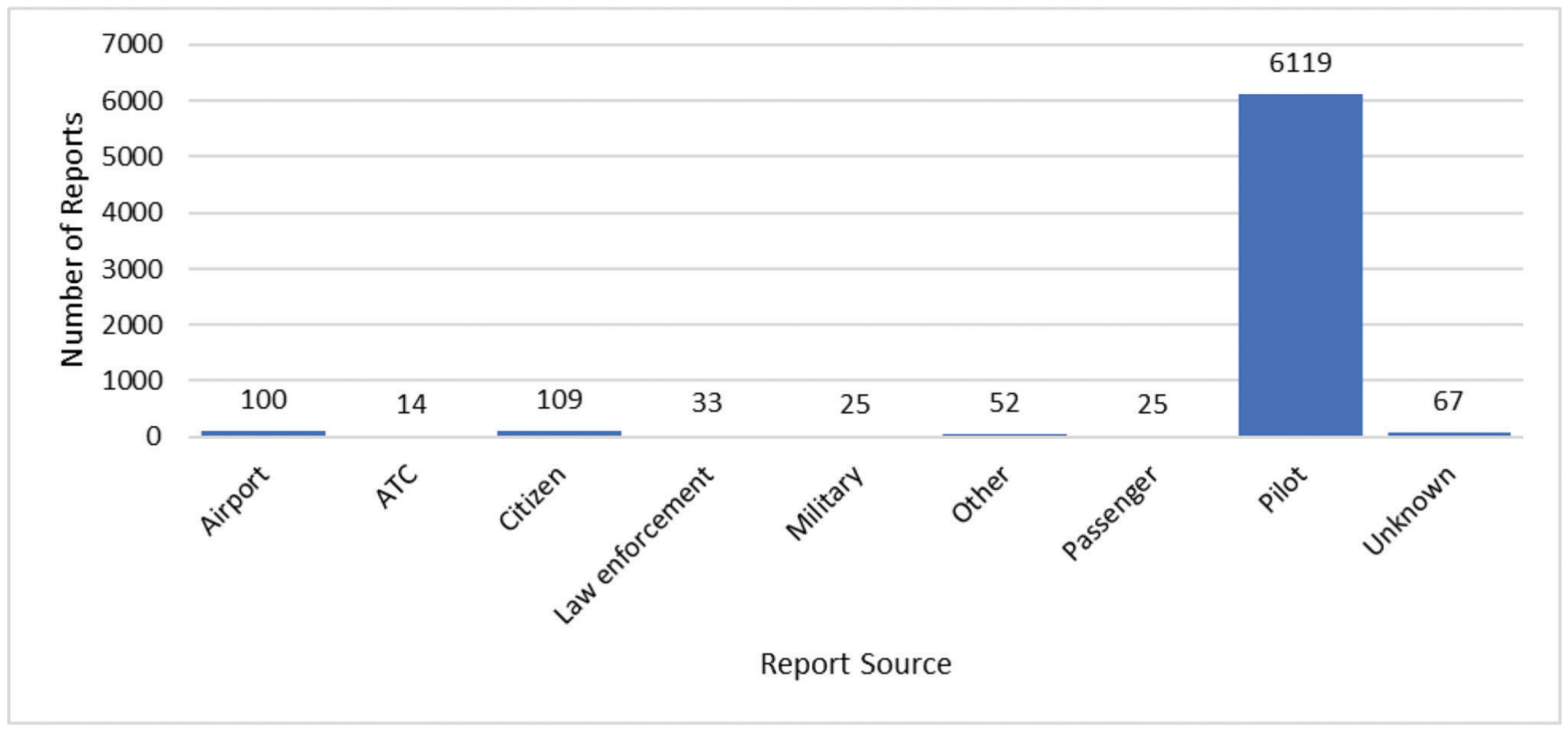

Figure 3. UAS sighting reports by report source (representing all 6,544 UAS sighting reports).

side). The data may reflect both visibility and where pilots tend to look while flying, in addition to the relative position of the UAS. Five percent of UASs are in front of the aircraft, which is generally consistent with the reported finding that only 3.3 percent of UAS sightings required the pilot to take evasive action.

Close encounters between UASs and manned aircraft are a serious safety concern (D'Souza et al., 2017; Kota et al., 2020; Lyons \& D'Souza, 2019; Olivares et al., 2017a, 2017b; Yu et al., 2021). About half of the UAS sighting reports include the distance between the manned aircraft and the UAS. This is larger than the 32 percent in the UAST (2017) study that reported the UAS-to-aircraft proximity, which suggests that UAS sighting reports are becoming more complete. As shown in Figure 8(a), pilots are more likely to report UASs that are below their aircraft, and are more likely to report UASs that are close to their aircraft, presumably because they present a greater hazard. For the UAS sightings in which the vertical distance between the UAS and the aircraft is recorded, 90 percent are within 1,000 feet of the aircraft, and 78 percent indicate that the UAS was within 500 feet of the aircraft. Figure 8(b) shows the horizontal distance between UAS and aircraft for UASs within 4,000 feet of the aircraft; this includes 93 percent of UAS sightings that record the horizontal distance. UASs as far away as three miles $(15,800$ feet) have been reported, although it is presumably harder to accurately estimate the distance of UASs that are farther away, and the reported UAS sightings at long distances skew the value of the average distance. As shown in Figure 8(b), the number of UAS sightings are symmetrically distributed and centered at zero, 79 percent of the reported UASs were within 1,000 feet of the aircraft, and
85 percent were within 2,000 feet of the aircraft. As more than half of the UAS sightings were reported within 400 feet of the aircraft, Figure 8(c) further shows the horizontal distance between UAS and aircraft for UASs within 400 feet of the aircraft. UAS sightings were most frequently reported when the UAS was less than 120 feet from the aircraft.

Considering the UAS sighting reports that include an altitude (87 percent of all reports), only nine percent of UASs were operated at or below 400 feet, and 91 percent of sightings occurred above 400 feet, greater non-compliance than the 70 percent reported by UAST in 2017. Both results reflect a lack of compliance with Part 107. Figure 9(a) shows the cumulative distribution of UAS sightings by altitude, which suggests that most of the reported UASs operated between 1,000 and 10,000 feet, which is surprising. Since most recreational UASs are not designed for altitudes above 10,000 feet (Turner, 2021), not surprisingly, there are few UASs reported above 10,000 feet due to limitations on operating characteristics. The highest recorded altitude for a UAS is 39,000 feet, 1,645 UAS sightings occurred above 4,000 feet, and 3,539 UAS sightings occurred between 400 and 4,000 feet. The average altitude for UAS sightings is 3,355 feet, and the median altitude is 2,200 feet, which are close to Gettinger and Michel's (2015) findings that the average altitude is $3,278.3$ feet and the median altitude is 2,100 feet.

The FAA not only restricts the altitude of UAS operations but also prohibits the operation of UASs in controlled airspace unless permission is obtained from ATC. UAS operators may be able to access controlled airspace at or below 400 feet with the support from the FAA UAS data exchange approach, commonly called Low 


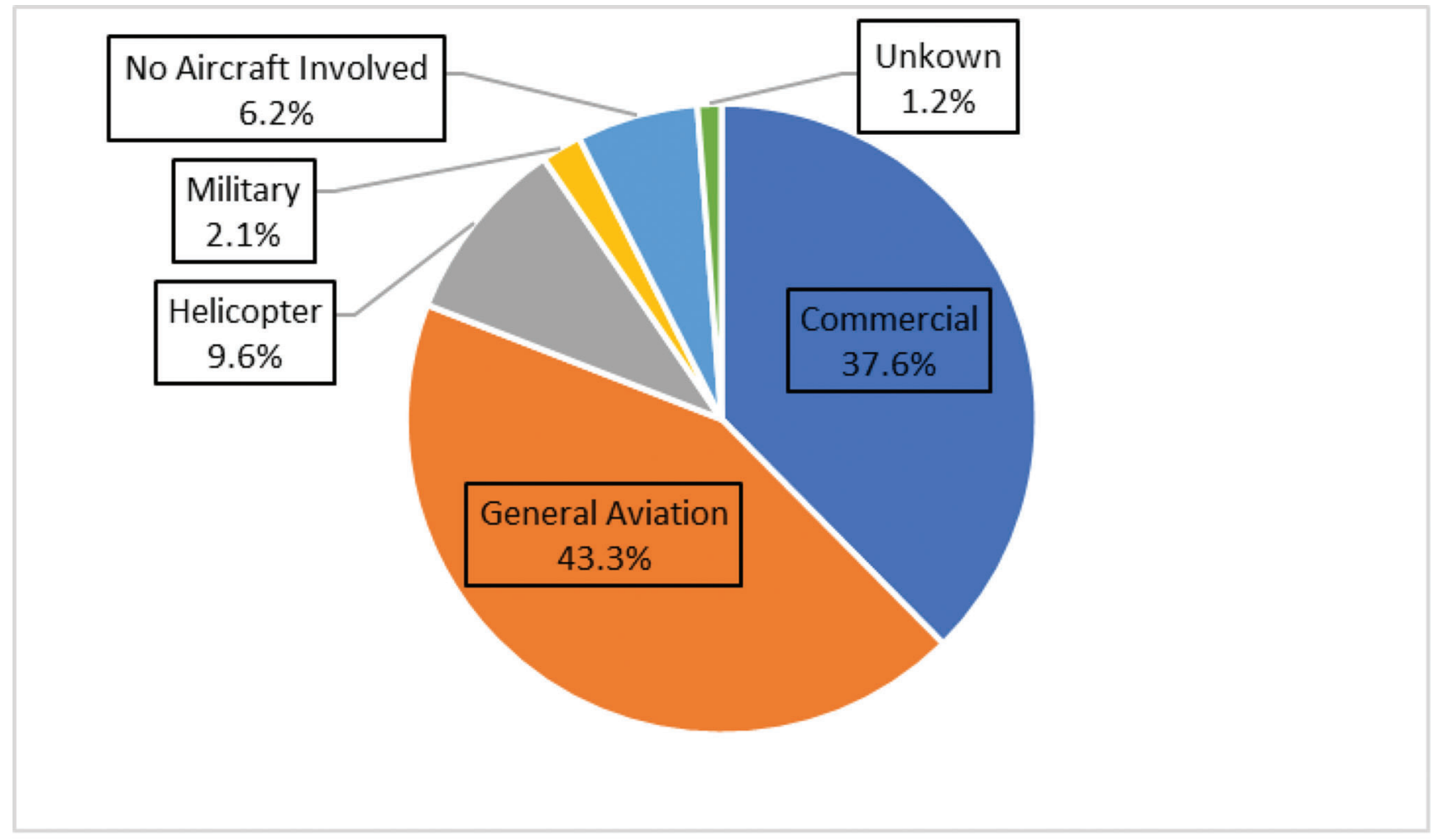

(a)

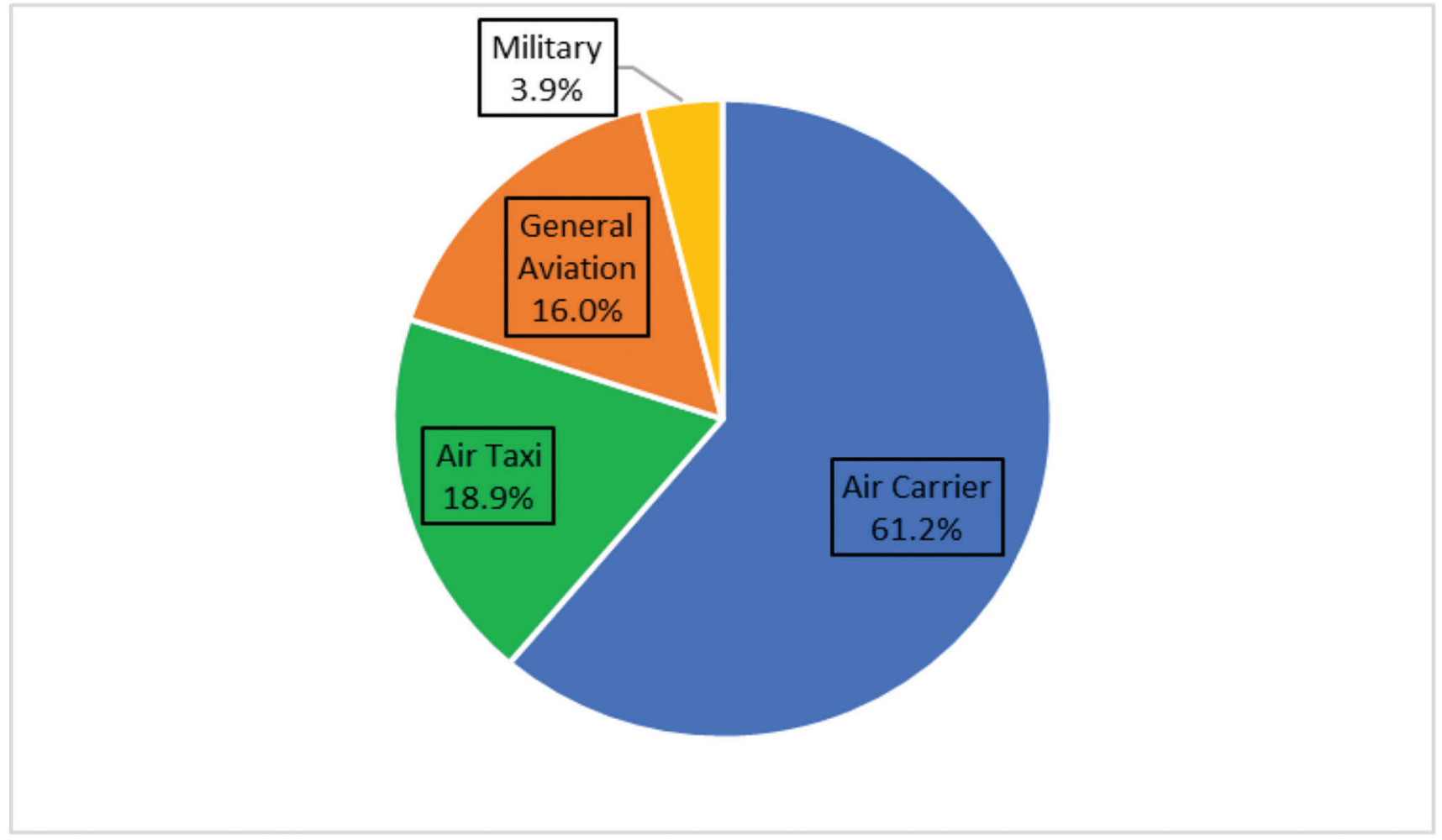

(b)

Figure 4. Types of aircraft operations: (a) UAS sightings; (b) flight operations. 


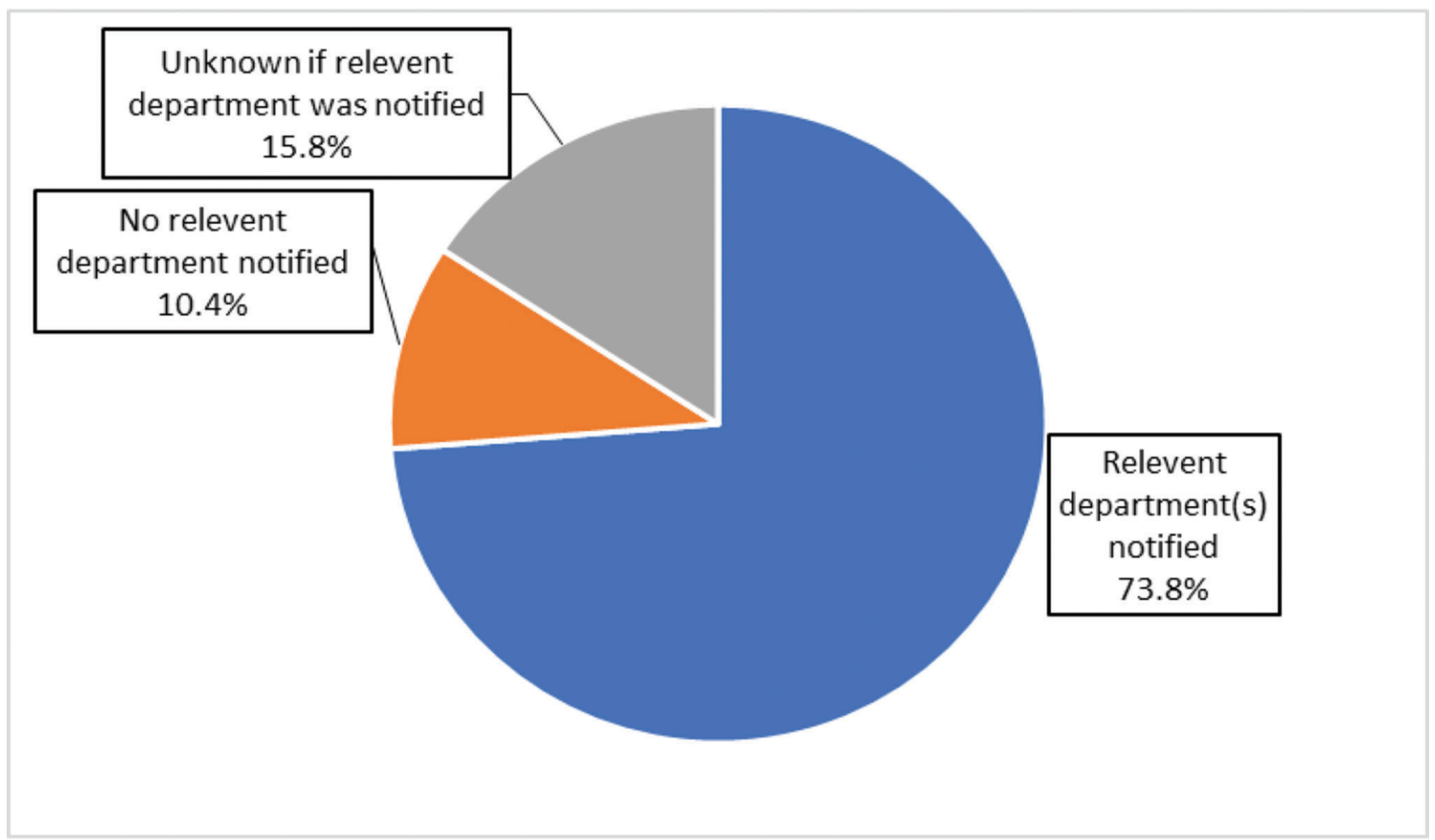

Figure 5. UAS sighting reports by law enforcement notification.

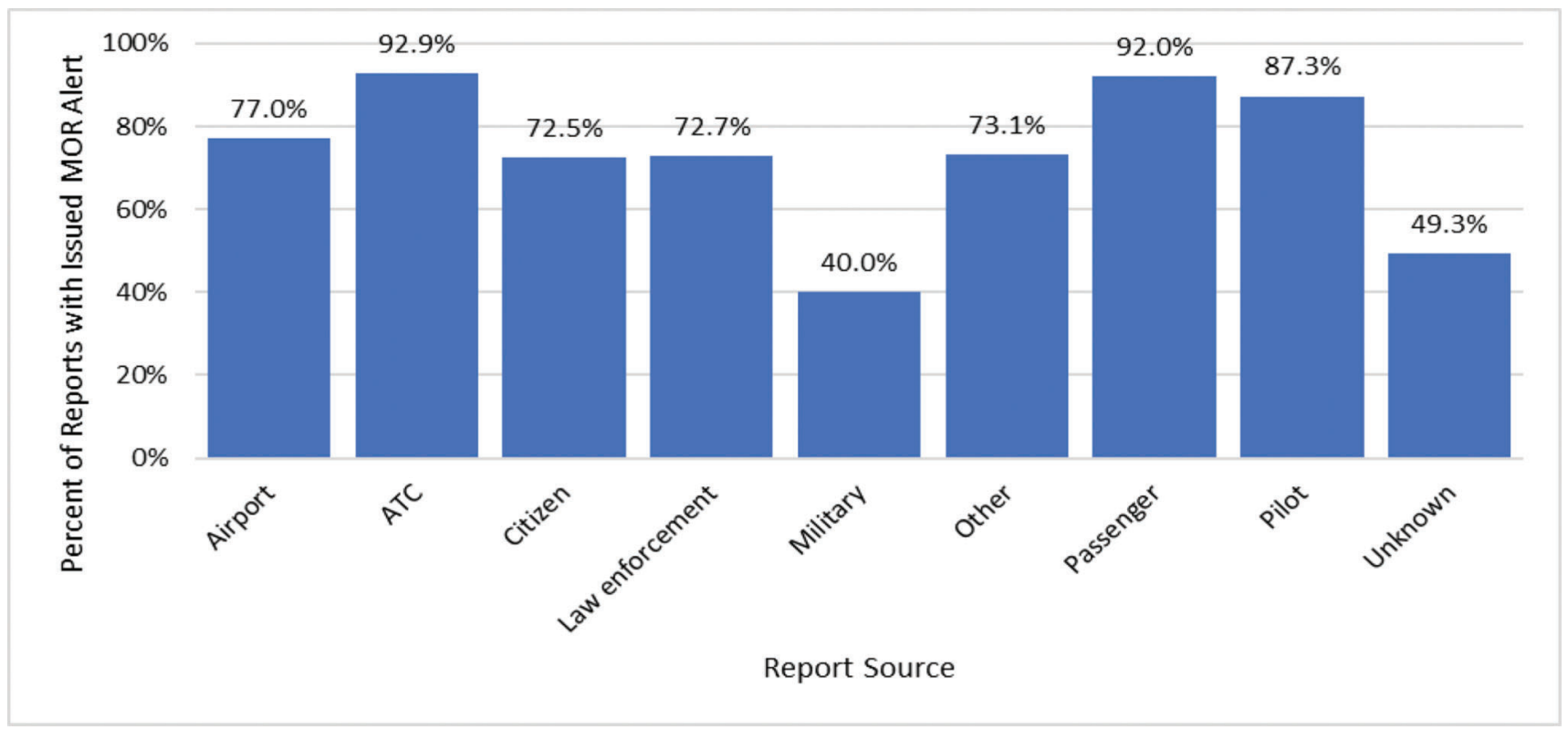

Figure 6. Percentage of UAS sightings resulting in a MOR.

Altitude Authorization and Notification Capability, which is a fast and convenient way for operators to obtain permission to fly in controlled airspace (FAA, 2020d). For UAS sightings for which the distance from an airport is recorded (72 percent of all UAS sightings), 57 percent occurred within five miles of the reported airport; 83 percent occurred within 10 miles of the reported airport; and 99 percent occurred within 30 miles of the airport. The average distance from an airport is 6.94 miles, and the median is 5 miles. A few UAS sightings occurred up to 180 miles from the reported airport; UAS sightings that are reported more than 50 miles from an airport may reflect the nearest commercial airport, or the airport where the aircraft took off or planned to land, rather than the nearest National 


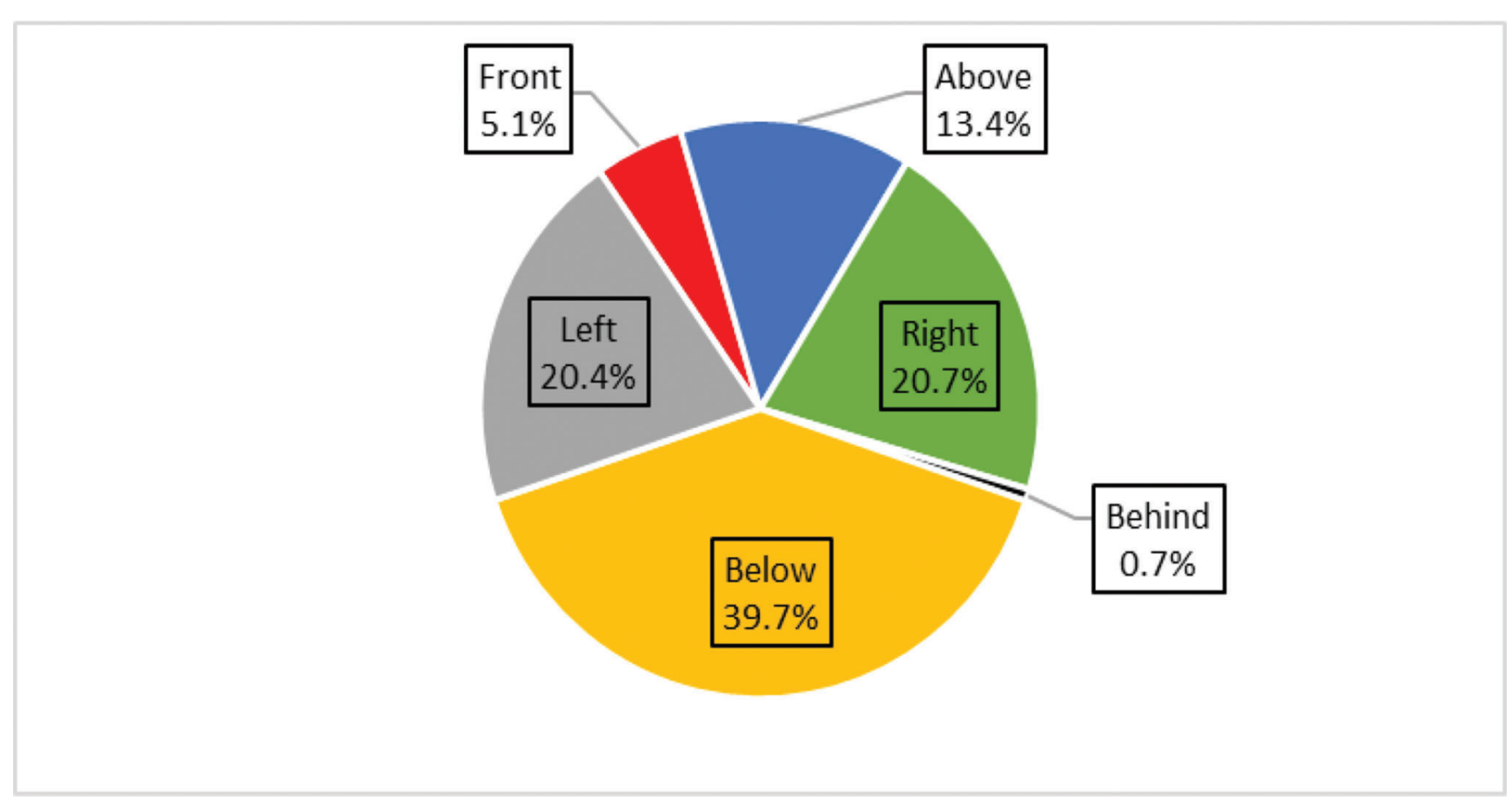

Figure 7. Position of UASs relative to aircraft.

Plan of Integrated Airport Systems (NPIAS) airport. Figure 9(b) shows the cumulative distribution of UAS sightings by distance from the airport, indicating that most of the UAS sightings occurred less than 10 miles from the reported airport.

Airport operators are interested in UASs in a proximity that may affect airport operations. Generally, UAS sightings beyond 10 miles of an airport occur at higher altitudes than UAS sightings within 10 miles of an airport, which is reasonable since aircraft tend to be at higher altitudes when they are farther from an airport. For UAS sightings with a recorded airport distance of more than 10 miles, the altitude of UASs was reported between zero and 37,000 feet, averaging 6,076 feet, which is within the altitude range of flights under visual flight rules. For UAS sightings within 10 miles of an airport, the altitude of UASs was reported between 20 and 39,000 feet, averaging 2,692 feet, which is higher than the usual traffic pattern altitude at 1,000 feet above ground level. Figure 10 shows UAS sightings by altitude and distance from the airport.

According to the FAA (2006), terminal radar approach control (TRACON) controllers hand the aircraft off to the ATC tower when an aircraft is within five miles of an airport and below 2,500 feet. Hence, airport operations should be responsible for UAS sightings within this range. Since TRACON controllers guide aircraft departing and approaching airports generally within a 30- to 50-mile radius up to 10,000 feet and aircraft that fly over that airspace, UAS sightings that occur between 30 and 50 miles from the airport and below 10,000 feet should be handled by TRACON controllers. When UAS sightings are reported more than 50 miles from the airport or above 10,000 feet, it is air route traffic controllers' responsibility to manage the UAS sightings.

The need for evasive action by a pilot of a manned aircraft to avoid a UAS implies a near miss. It is affected by the distance and relative motion between an aircraft and UAS, whether there is time to take evasive action, and the speed of the aircraft. Fortunately, pilots rarely have to take evasive action to avoid UASs, as shown in Table 3, which provides information about pilots' evasive maneuvers by aircraft type. Overall, pilots take evasive action in only 3.3 percent of cases. Pilots of GA aircraft and helicopters are more likely to take evasive action than pilots of commercial aircraft, which may be due to the altitudes at which they commonly fly, the lower speeds at which they travel, their ability to change course more quickly, and their vulnerability to damage if there is a collision with a UAS.

These results are consistent with previous studies (Gettinger \& Michel, 2015; UAST, 2017) and also with the Heinrich Law (Heinrich, 1941), which states that "for every accident that causes a major injury, there are 29 accidents that cause minor injuries and 300 accidents that cause no injuries." Figure 11 illustrates the Heinrich Law and its application to UAS sightings.

The frequency of UAS sightings varies significantly, depending on the state. States that have large populations and cities with higher population densities have more UAS sightings. Table 4 provides a breakdown of reports, population, NPIAS airports, and primary airports by state 
(FAA, 2018b; United States Census Bureau, 2019). As shown in Table 4:

- The four states with the most UAS sightings are California, Florida, New York, and Texas; these states also have the largest populations. UAS sightings from the top ten states account for two-thirds of UAS sighting reports and reflect about half of the U.S. population.

- The states with the most NPIAS airports are Alaska, Texas, California, and Florida; except for Alaska, the other three states have the most UAS sightings.

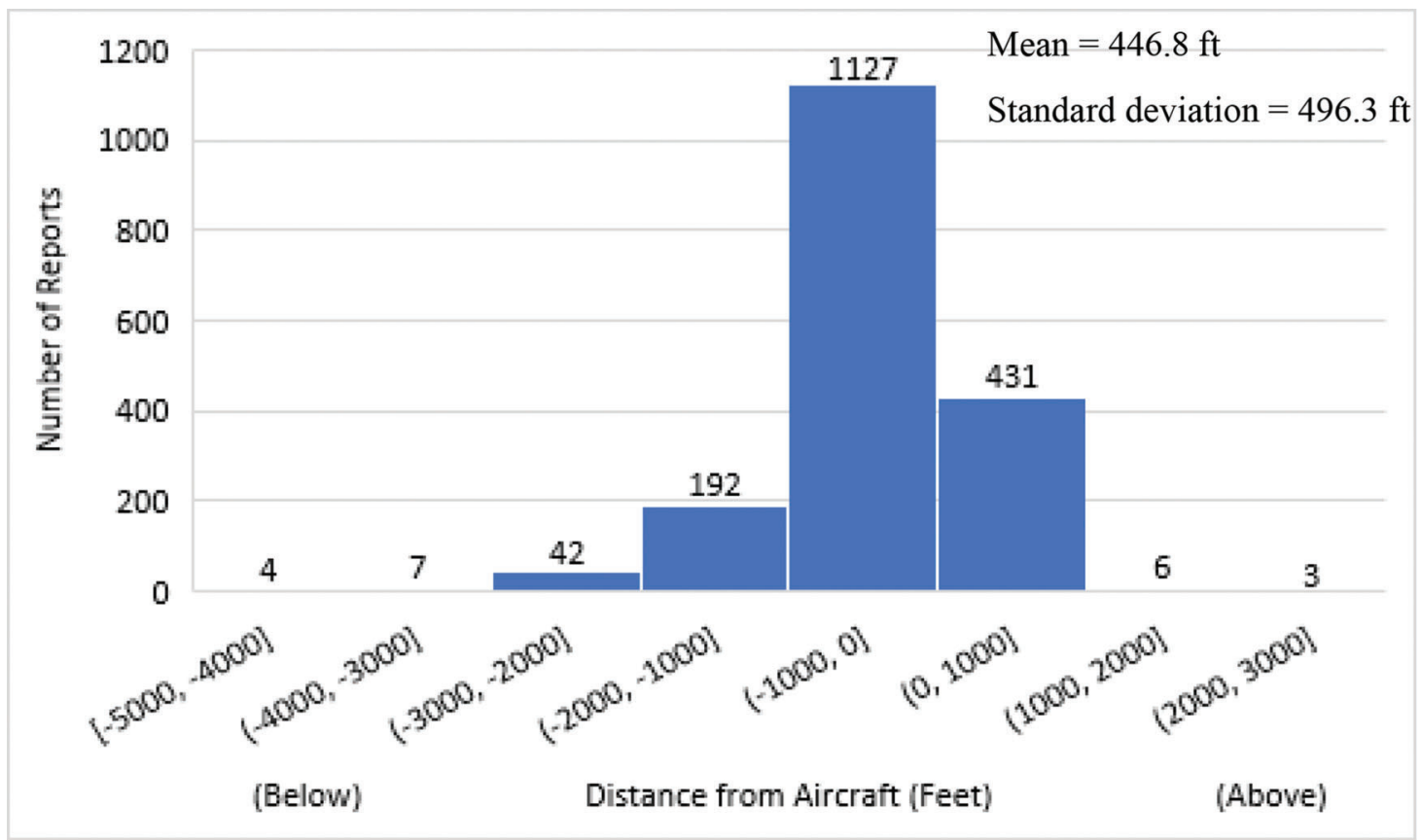

(a)

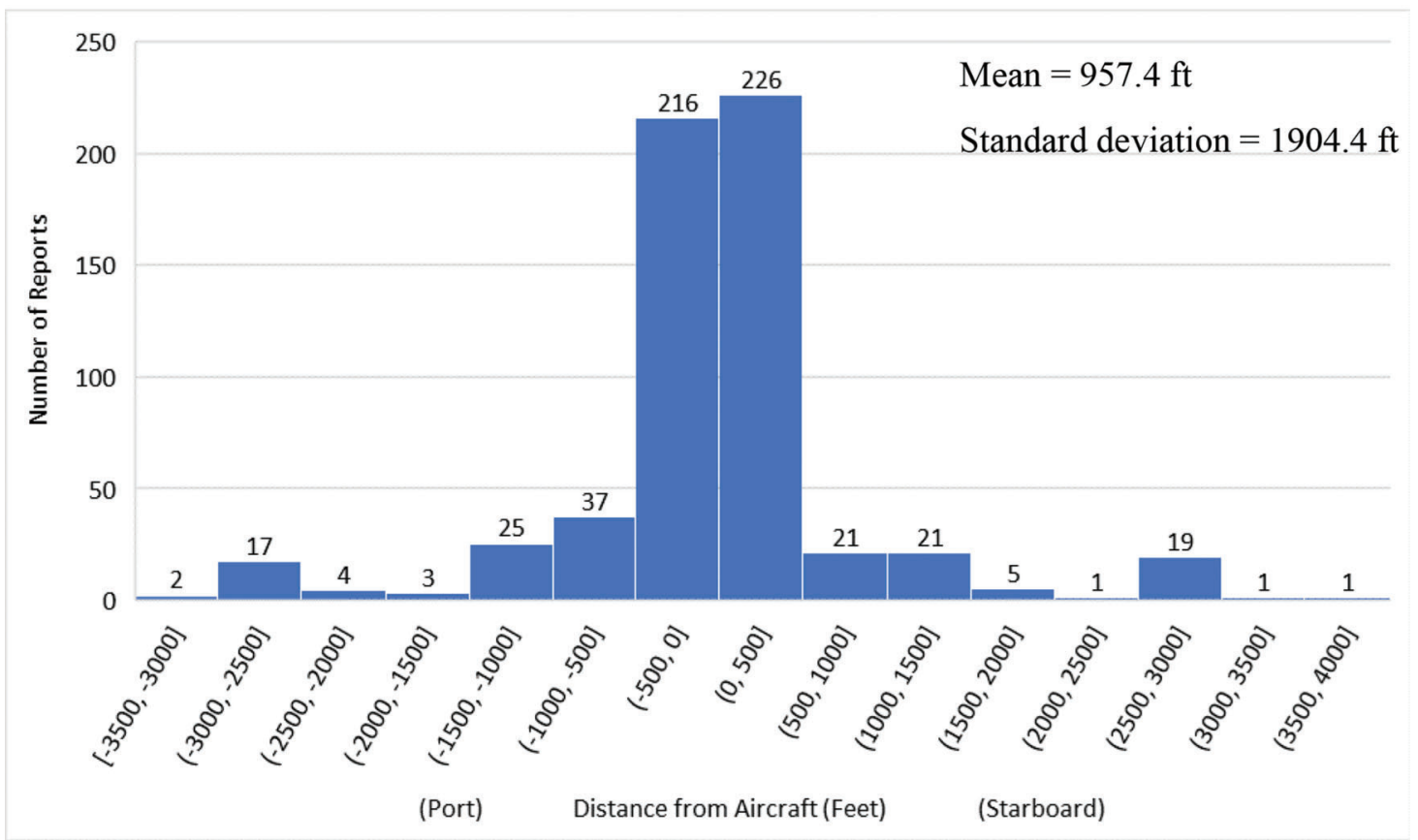

(b)

Figure 8. Continued. 


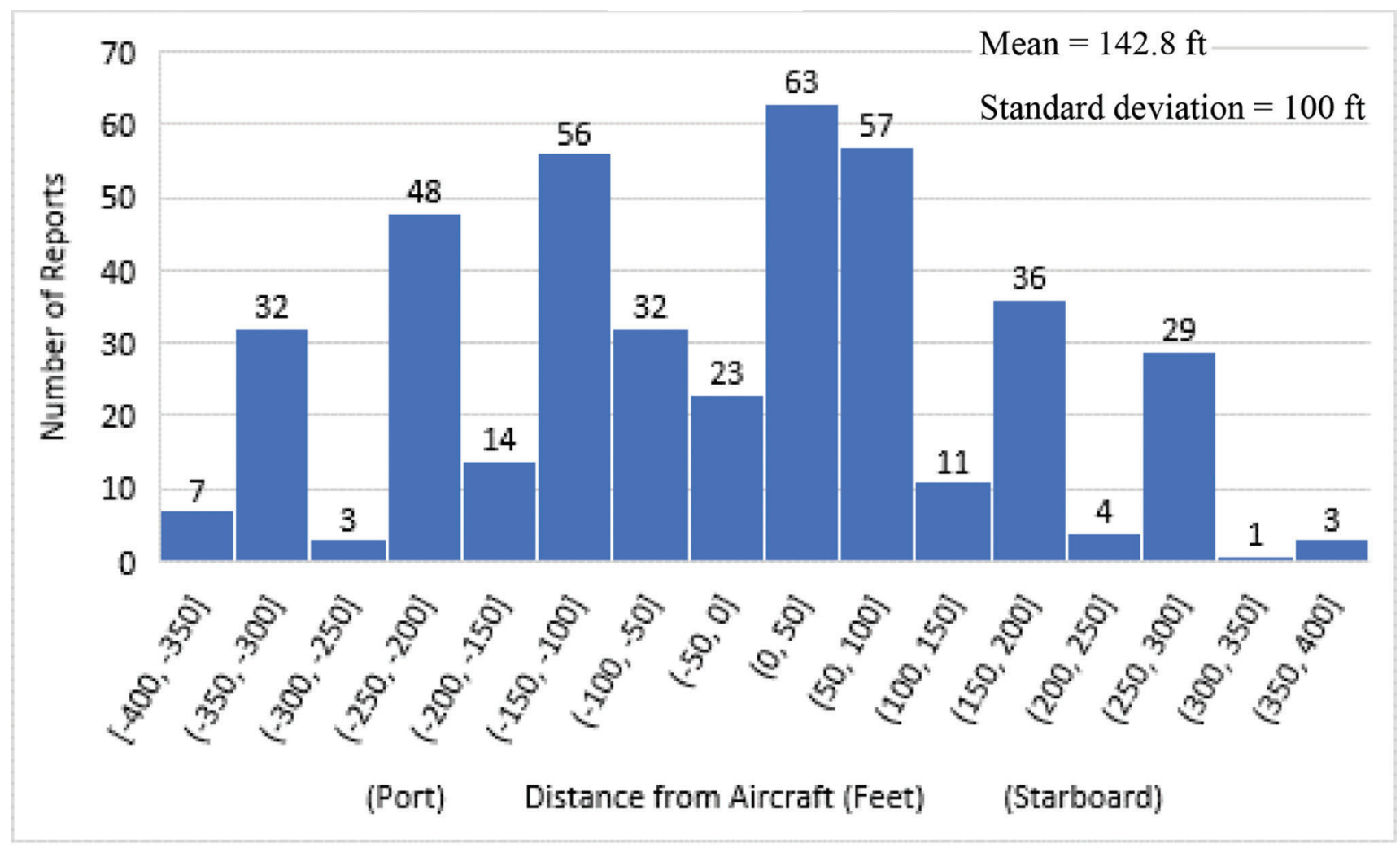

(c)

Figure 8. Proximity of UAS to aircraft: (a) vertical distance between UAS and aircraft (above or below aircraft); (b) horizontal distance between UAS and aircraft within 4,000 feet (port or starboard side of aircraft); (c) horizontal distance between UAS and aircraft within 400 feet (port or starboard side of aircraft).

- The states with the most primary airports are California, Florida, New York, and Texas; these four states are the top four states for UAS sightings.

- As the fifth-ranked state, New Jersey has a lot of UAS sightings relative to the population, the percent of NPIAS airports, and the percent of primary airports. Half of the UAS sightings in New Jersey occurred close to EWR, which is the fifth airport in terms of the number of UAS sightings and located in the New York metropolitan area. Hence, it is not surprising that EWR had the first and the only UAS sighting that occurred at a major airport in the USA.

Table 5 displays the number and percentage of UAS sighting reports by airport category, with supporting airport statistics. Between September 2016 and August 2019, a total of 856 airports had UAS sightings, including 270 primary airports and 586 non-primary airports. UAS sightings are more likely to be reported close to primary airports, especially large and medium hub airports. Large and medium hub airports account for 1.8 percent of NPIAS airports; however, 48.9 percent of UAS sightings occurred at large and medium hub airports. Similarly, primary airports account for 11.4 percent of NPIAS airports but had 67 percent of all UAS sightings. All large and medium hub airports had at least one UAS sighting, and UAS sightings at these airports would be more disruptive in terms of impacts to aircraft operations at the airport, and propagating through the airport system. Sixty-six (91.7 percent) small hub airports also had at least one UAS sighting, but UAS sightings are less often reported at non-hub airports. There are relatively few UAS sightings at commercial service and GA airports.

Table 6 presents the top 20 airports in terms of the number of UAS sightings, which are all large hub airports. It appears that UAS sightings are more likely in populous urban areas since the top five airports (LGA, LAX, JFK, ORD, EWR) are close to the three largest cities (New York, Los Angeles, and Chicago). LGA had the most UAS sightings (311), followed by LAX (210 UAS sightings), and JFK (157 UAS sightings). These three airports are also top ranked when UAS sightings are normalized with respect to annual operations.

\section{Discussion}

Analysis of UAS sighting reports confirms some findings from previous studies and expands on previous studies to consider the potential impact on airport operations. Findings suggest that the likelihood of a UAS sighting varies depending on the time of year, time of day, aircraft 


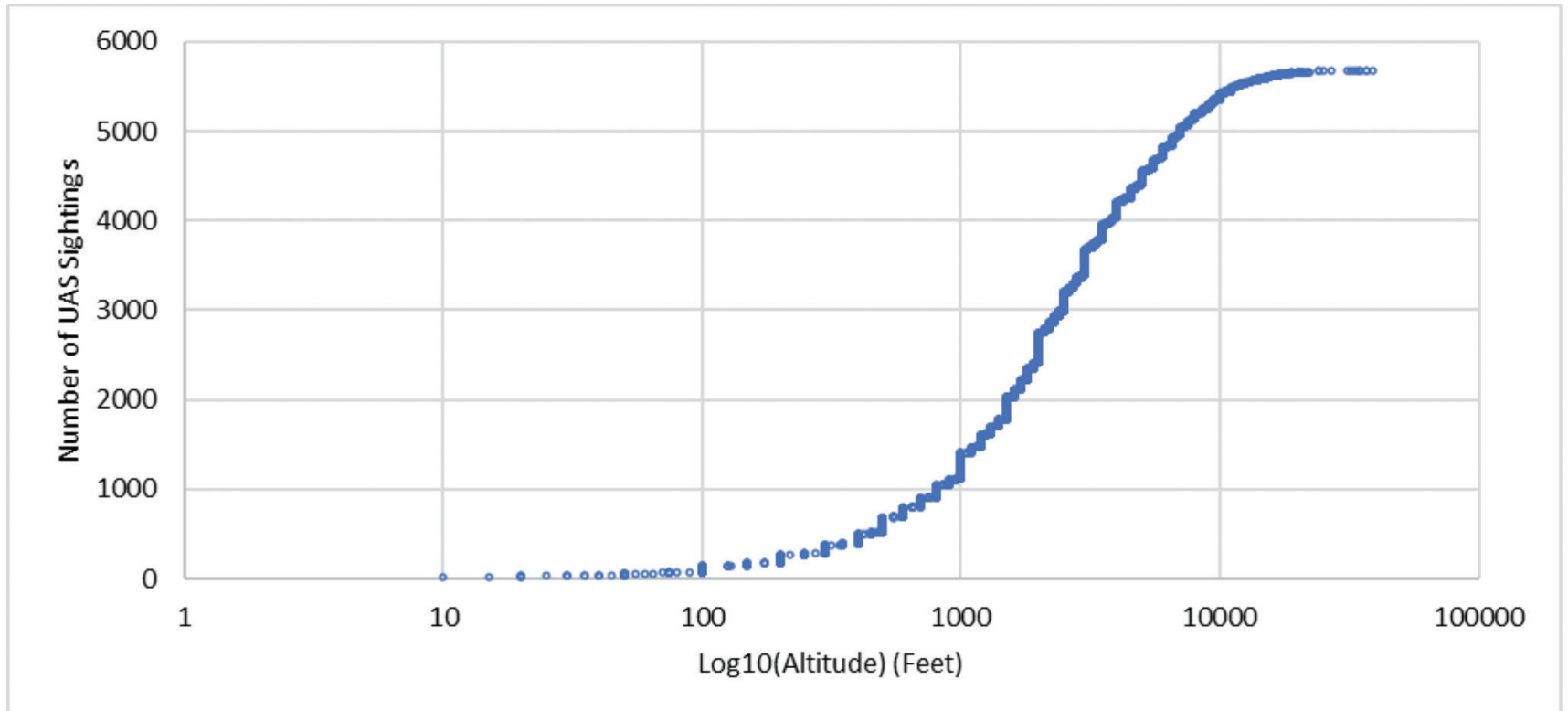

(a)

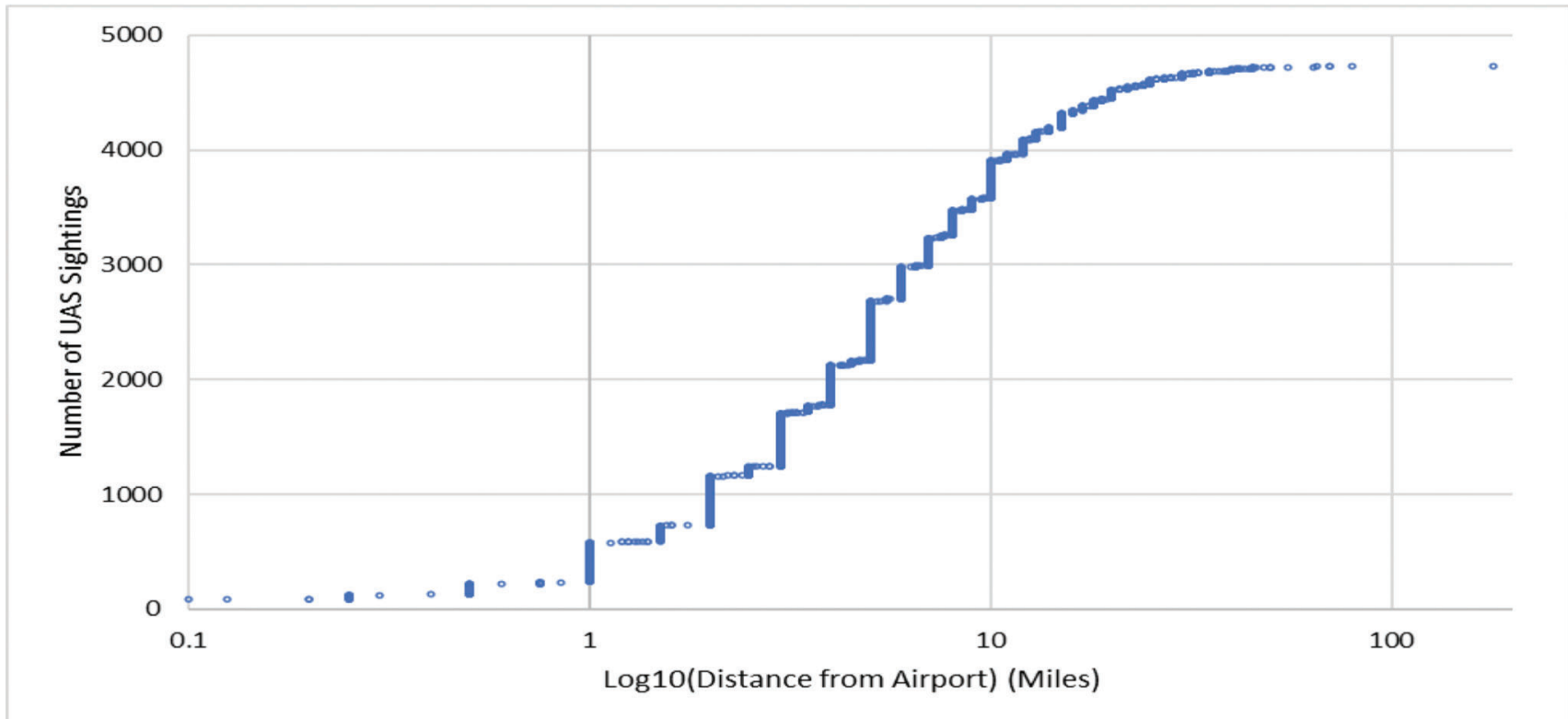

(b)

Figure 9. Cumulative distribution of UAS sightings: (a) by altitude (excluding UAS sightings that reported the altitude was zero); (b) by distance from the airport (excluding UAS sightings that reported the distance was zero).

type, proximity to manned aircraft, and position of UAS relative to manned aircraft. Similarly, primary airports, particularly large and medium hub airports, may be more affected by UAS sightings, both due to the frequency of UAS sightings and due to the greater impact associated with a disruption to airport operations. The impact includes both flight operations and associated economic losses. The likelihood of UAS sightings is summarized in Table 7. As shown in Table 7, it may be appropriate to focus resources and attention on large and medium hub airports, because a UAS sighting at these airports is not only more likely, but also would have a greater impact. The impact of UAS sightings on airport operations has been evidenced dramatically at airports in other countries, including Gatwick and Dubai. Fortunately, the only UAS sighting of note in the USA was at EWR and had a minimal impact.

Analysis of UAS sighting reports in the context of airport safety lends a new dimension that should be considered by airport operators and the FAA. Clearly, safety at 


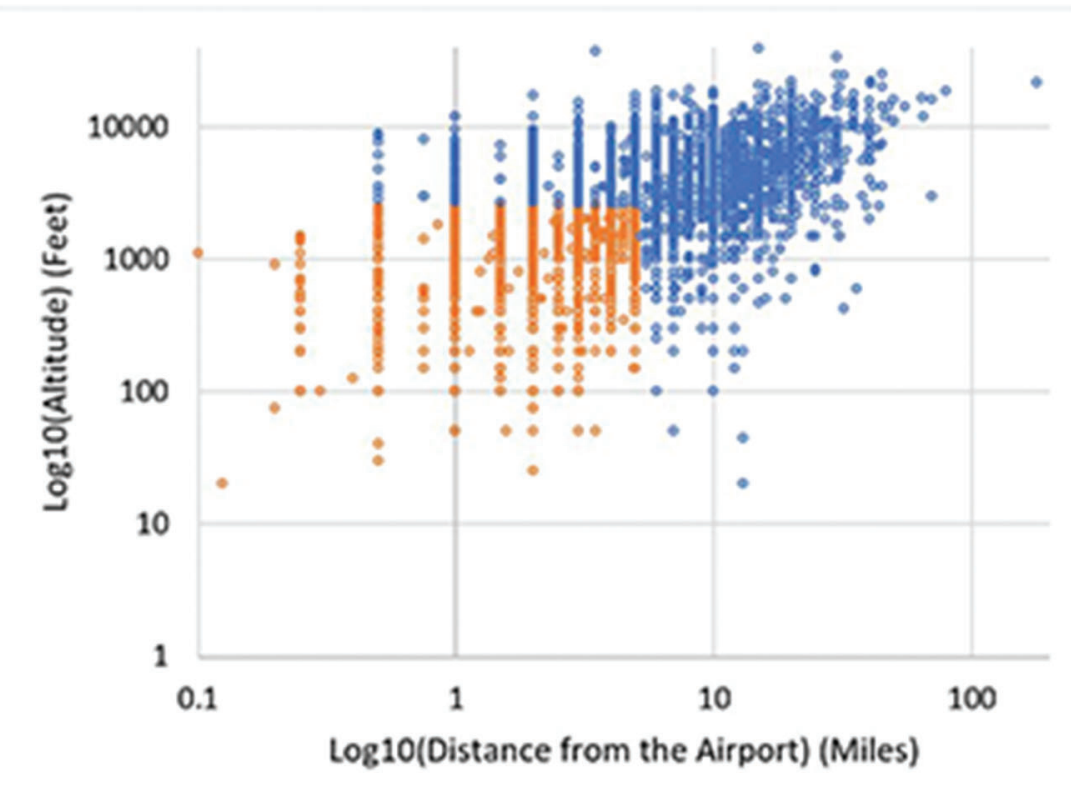

- UAS occurred within five miles of an airport and below 2,500 feet

- UAS occurred more than five miles from an airport or above 2,500 feet

Figure 10. UAS sightings by altitude and distance from the airport.

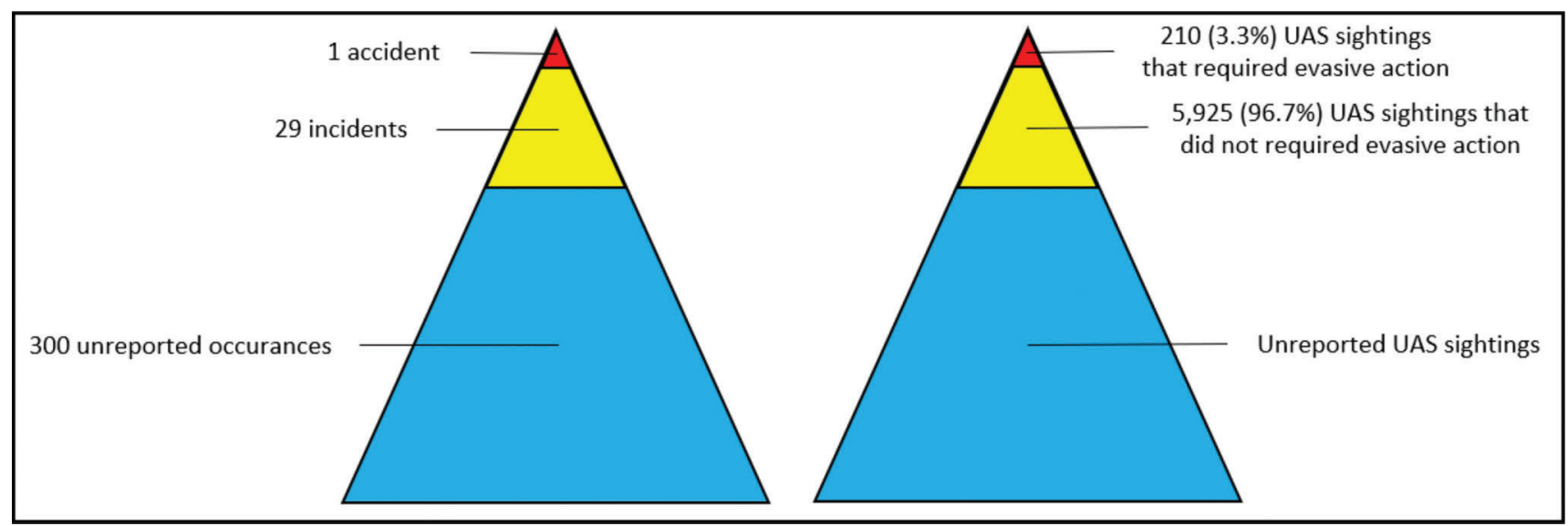

Figure 11. The Heinrich Law (left) and its application to UAS sightings (right).

Table 3

UAS sighting reports by aircraft type and evasive action (percent and number).

\begin{tabular}{|c|c|c|c|c|c|c|}
\hline Report & Total & GA aircraft & $\begin{array}{l}\text { Commercial } \\
\text { aircraft }\end{array}$ & Helicopter & $\begin{array}{c}\text { Military } \\
\text { aircraft }\end{array}$ & $\begin{array}{l}\text { Aircraft type } \\
\text { unknown }\end{array}$ \\
\hline Total UAS sightings & $100.0 \%(6,135)$ & $46.2 \%(2,833)$ & $37.6 \%(2,461)$ & $10.2 \%(627)$ & $2.2 \%(135)$ & $1.3 \%(80)$ \\
\hline $\begin{array}{l}\text { UAS sightings did not require } \\
\text { evasive action }\end{array}$ & $96.7 \%(5,925)$ & $45.7 \%(2,706)$ & $41.3 \%(2,445)$ & $9.6 \%(567)$ & $2.2 \%(128)$ & $1.3 \%(80)$ \\
\hline $\begin{array}{l}\text { UAS sightings that required } \\
\text { evasive action }\end{array}$ & $3.3 \%(210)$ & $60.5 \%(127)$ & $7.6 \%(16)$ & $28.6 \%(60)$ & $3.3 \%(7)$ & $0.0 \%(0)$ \\
\hline
\end{tabular}

large and medium hub airports is the greatest priority, and focusing attention on these 61 airports can help ensure that resources will have the most impact to ensure safety and continuity of airport operations.

While most UAS sightings do not cause an incident or accident and only a small proportion of UAS sightings may present a potential threat to aviation safety, this research confirmed the validity of the Heinrich Law as it applies to UAS sightings. In this analysis, about 3.3 percent of UAS sightings required an evasive maneuver, and about 96.7 percent did not require an evasive maneuver. This is consistent with Heinrich's ratio of one accident for every 
Table 4

UAS sighting reports by state (top 35, including Washington, DC).

\begin{tabular}{|c|c|c|c|c|c|c|}
\hline Rank & State & $\begin{array}{l}\text { Number } \\
\text { (percent) } \\
\text { of reports }\end{array}$ & $\begin{array}{l}\text { Population } \\
\text { in thousand } \\
\text { (percent) }\end{array}$ & $\begin{array}{c}\text { Number (percent) } \\
\text { of NPIAS } \\
\text { airports }\end{array}$ & $\begin{array}{c}\text { Number (percent) } \\
\text { of primary } \\
\text { airports }\end{array}$ & $\begin{array}{c}\text { Average number } \\
\text { of reports per } \\
\text { primary airport }\end{array}$ \\
\hline 1 & California & $1,097(16.9 \%)$ & $39,512(12.0 \%)$ & $190(5.8 \%)$ & $22(6.0 \%)$ & 49.9 \\
\hline 2 & Florida & $777(12.0 \%)$ & $21,478(6.5 \%)$ & $100(3.0 \%)$ & $20(5.5 \%)$ & 38.9 \\
\hline 3 & New York & $638(9.8 \%)$ & $19,454(5.9 \%)$ & $83(2.5 \%)$ & $16(4.4 \%)$ & 39.9 \\
\hline 4 & Texas & $560(8.6 \%)$ & $28,996(8.8 \%)$ & $210(6.4 \%)$ & $24(6.6 \%)$ & 23.3 \\
\hline 5 & New Jersey & $237(3.7 \%)$ & $8,882(2.7 \%)$ & $24(0.7 \%)$ & $3(0.8 \%)$ & 79.0 \\
\hline 6 & Illinois & $228(3.5 \%)$ & $12,672(3.9 \%)$ & $85(2.6 \%)$ & $10(2.7 \%)$ & 22.8 \\
\hline 7 & Arizona & $227(3.5 \%)$ & $7,279(2.2 \%)$ & $59(1.8 \%)$ & $9(2.5 \%)$ & 25.2 \\
\hline 8 & Georgia & $191(2.9 \%)$ & $10,617(3.2 \%)$ & $97(2.9 \%)$ & $7(1.9 \%)$ & 27.3 \\
\hline 9 & Washington & $178(2.7 \%)$ & $7,615(2.3 \%)$ & $64(1.9 \%)$ & $10(2.7 \%)$ & 17.8 \\
\hline 10 & Pennsylvania & $173(2.7 \%)$ & $12,802(3.9 \%)$ & $63(1.9 \%)$ & $9(2.5 \%)$ & 19.2 \\
\hline 11 & North Carolina & $163(2.5 \%)$ & $10,488(3.2 \%)$ & $72(2.2 \%)$ & $10(2.7 \%)$ & 16.3 \\
\hline 12 & Massachusetts & $149(2.3 \%)$ & $6,893(2.1 \%)$ & $28(0.8 \%)$ & $6(1.6 \%)$ & 24.8 \\
\hline 13 & Colorado & $139(2.1 \%)$ & $5,759(1.8 \%)$ & $49(1.5 \%)$ & $9(2.5 \%)$ & 15.4 \\
\hline 14 & Nevada & $129(2.0 \%)$ & $3,080(0.9 \%)$ & $30(0.9 \%)$ & $5(1.4 \%)$ & 25.8 \\
\hline 15 & Virginia & $124(1.9 \%)$ & $8,536(2.6 \%)$ & $47(1.4 \%)$ & $8(2.2 \%)$ & 15.5 \\
\hline 16 & Michigan & $112(1.7 \%)$ & $9,987(3.0 \%)$ & $95(2.9 \%)$ & $15(4.1 \%)$ & 7.5 \\
\hline 17 & Washington, DC & $102(1.6 \%)$ & $706(0.2 \%)$ & $1(0.0 \%)$ & $0(0.0 \%)$ & 0.0 \\
\hline 18 & Tennessee & $89(1.4 \%)$ & $6,829(2.1 \%)$ & $69(2.1 \%)$ & $5(1.4 \%)$ & 17.8 \\
\hline 19 & Ohio & $86(1.3 \%)$ & $11,689(3.6 \%)$ & $99(3.0 \%)$ & $7(1.9 \%)$ & 12.3 \\
\hline 20 & Oregon & $75(1.2 \%)$ & $4,218(1.3 \%)$ & $57(1.7 \%)$ & $5(1.4 \%)$ & 15.0 \\
\hline 21 & South Carolina & $72(1.1 \%)$ & $5,149(1.6 \%)$ & $53(1.6 \%)$ & $6(1.6 \%)$ & 12.0 \\
\hline 22 & Maryland & $68(1.0 \%)$ & $6,046(1.8 \%)$ & $18(0.5 \%)$ & $3(0.8 \%)$ & 22.7 \\
\hline 23 & Utah & $68(1.0 \%)$ & $3,206(1.0 \%)$ & $36(1.1 \%)$ & $5(1.4 \%)$ & 13.6 \\
\hline 24 & Minnesota & $66(1.0 \%)$ & $5,640(1.7 \%)$ & $97(2.9 \%)$ & $8(2.2 \%)$ & 8.3 \\
\hline 25 & Louisiana & $61(0.9 \%)$ & $4,649(1.4 \%)$ & $56(1.7 \%)$ & $7(1.9 \%)$ & 8.7 \\
\hline 26 & Connecticut & $59(0.9 \%)$ & $3,565(1.1 \%)$ & $13(0.4 \%)$ & $2(0.5 \%)$ & 29.5 \\
\hline 27 & Alabama & $57(0.9 \%)$ & $4,903(1.5 \%)$ & $74(2.2 \%)$ & $5(1.4 \%)$ & 11.4 \\
\hline 28 & Kentucky & $55(0.8 \%)$ & $4,468(1.4 \%)$ & $55(1.7 \%)$ & $5(1.4 \%)$ & 11.0 \\
\hline 29 & Missouri & $53(0.8 \%)$ & $6,137(1.9 \%)$ & $75(2.3 \%)$ & $5(1.4 \%)$ & 10.6 \\
\hline 30 & Hawaii & $51(0.8 \%)$ & $1,416(0.4 \%)$ & $15(0.5 \%)$ & $7(1.9 \%)$ & 7.3 \\
\hline 31 & Oklahoma & $50(0.8 \%)$ & $3,957(1.2 \%)$ & $100(3.0 \%)$ & $4(1.1 \%)$ & 12.5 \\
\hline 32 & Indiana & $46(0.7 \%)$ & $6,732(2.1 \%)$ & $65(2.0 \%)$ & $4(1.1 \%)$ & 11.5 \\
\hline 33 & Alaska & $35(0.5 \%)$ & $732(0.2 \%)$ & $256(7.8 \%)$ & $29(7.9 \%)$ & 1.2 \\
\hline 34 & Wisconsin & $31(0.5 \%)$ & $5,822(1.8 \%)$ & $87(2.6 \%)$ & $8(2.2 \%)$ & 3.9 \\
\hline 35 & New Mexico & $26(0.4 \%)$ & $2,097(0.6 \%)$ & $50(1.5 \%)$ & $4(1.1 \%)$ & 6.5 \\
\hline
\end{tabular}

Note. Data reflect the NPIAS report published in 2018 and which was revised on October 6, 2020.

29 incidents. The Heinrich Law also suggests that there are 300 unreported occurrences for every accident. This would suggest there may have been about 63,000 unreported UAS sightings. It is worthwhile to consider how to capture information about many unreported UAS sightings. However, a previous study conducted by Cardosi et al. (2018) found that collisions were narrowly avoided in 25 percent of MORs involving UASs, and in conflicts, there was no time to maneuver. The difference could be due to the method of reporting or the level of detail in each report. Also, air traffic controllers may be more likely to file a MOR when the UAS is close to the manned aircraft or pilots do not have sufficient time to maneuver. Although UAS sightings are less severe than narrowly avoided collisions involving UASs, it may be helpful if the FAA described the requirements of hosting UAS sightings data on the website.
The UAS Sighting Reports database provides a tool to begin to explore the potential issue of interaction between aircraft and UASs, as evidenced by these findings. Although there may be concerns regarding the database since it is comprised of voluntary reports, including its comprehensiveness (e.g., whether it reports all UAS sightings) and the need for additional validation (e.g., some UAS sighting reports should not be included), the database is the most comprehensive and accessible currently available for analysis and is the product of the FAA, a global leader in aviation and aviation safety. The recent requirement for Remote ID for UAS will be useful for validation of data provided in the UAS sighting reports. Information gathered from UAS Remote ID in conjunction with aircraft transponder data may be used to provide additional information on potential interaction between UASs and aircraft, which will be useful to help identify the potential impact of UASs at airports. 

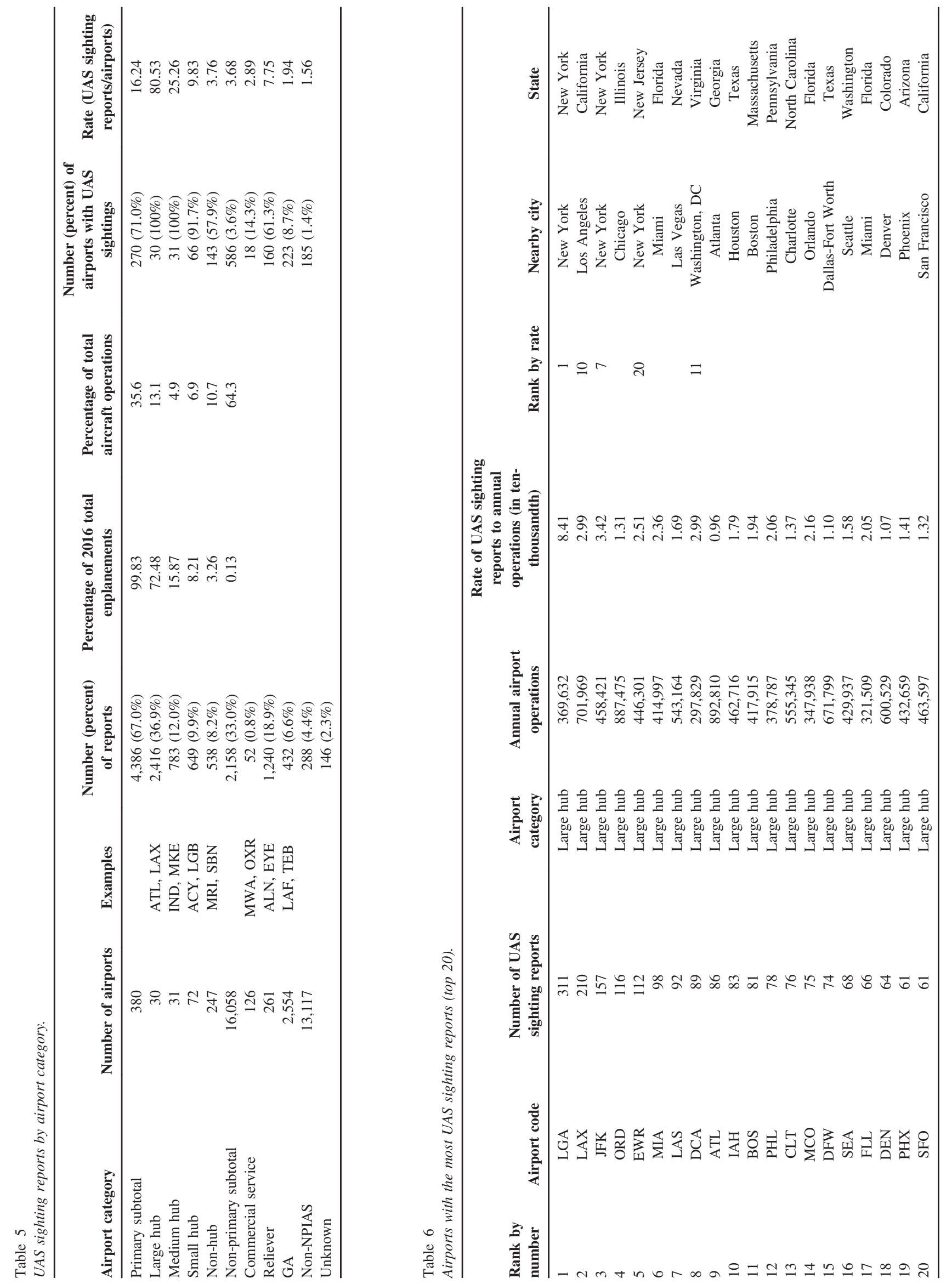
Table 7

Likelihood of UAS sightings by characteristics.

\begin{tabular}{|c|c|c|c|}
\hline \multirow{2}{*}{$\begin{array}{l}\text { Characteristics of } \\
\text { UAS sightings }\end{array}$} & \multicolumn{3}{|c|}{ Likelihood } \\
\hline & Low & Medium & High \\
\hline Airport category & $\begin{array}{c}\text { Non-hub, commercial service, and GA } \\
\text { airports }\end{array}$ & Small hub and reliever airports & Large and medium hub airports \\
\hline Airport location & Rural area & Suburban area & Urban area \\
\hline Month & January, February, November, December & March, April, September, October & May, June, July, August \\
\hline State population & Less than $0.5 \%$ of the U.S. population & $\begin{array}{c}\text { Between } 0.5 \% \text { and } 2 \% \text { of the U.S. } \\
\text { population }\end{array}$ & More than $2 \%$ of the U.S. population \\
\hline Time of day & 12 a.m. to 9 a.m. and 9 p.m. to 12 a.m. & 9 a.m. to 11 a.m. and 6 p.m. to 9 p.m. & 11 a.m. to 6 p.m. \\
\hline
\end{tabular}

Since the value of the UAS sighting database is enhanced by detailed and complete information, it may be helpful if the FAA promoted the UAS sighting database and method for filing reports to pilots and airport operators. It may be helpful if the FAA widely disseminated examples of the kind of information that should be included in a complete UAS sighting report. Similarly, it would be useful to provide separate fields for key data such as UAS altitude, proximity to the closest airport, airport code, type of manned aircraft, proximity to manned aircraft, position of UAS relative to manned aircraft, if evasive action is taken, if law enforcement is notified, if an MOR alert is filed, and report source. With the enhancement of details in the report and the FAA's continuing publication of the database, UAS sightings will not only become more useful for supporting additional analysis but also increase awareness of the database, and help the FAA conduct research and development activities in the area of UAS sightings at and near airports.

The impact of the UAS sighting database may be expanded, if the FAA simplifies the UAS sighting reporting procedure and creates an online reporting system, analogous to the FAA Wildlife Strike Database, rather than requiring reports to be filed through the FSDO. The Wildlife Strike Database is widely used by airlines, airport personnel, and pilots, and the resulting database is well known and provides very comprehensive data for airport operators and researchers.

\section{Conclusions}

UAS sightings have become an increasing source of concern for the FAA and airport operators. Characteristics of UAS sightings and these characteristics in the context of airport operations and safety are presented and discussed in this study. While all airports may be potentially affected by UAS sightings, larger airports, airports in larger cities, and airports in California, Florida, New York, and Texas may be more likely to be affected. Analysis of UAS sightings in this research suggests that it would be worthwhile to focus efforts on primary airports, specifically large and medium hub airports. Given the value of the UAS Sighting Reports database, it would be helpful to simplify the reporting process, increase outreach efforts regarding the existence of the database, and provide additional information regarding the verification process for UAS sightings, to increase the validity of and confidence in the database. Additional areas for future research include analysis of the impact of UAS-oriented incidents and accidents, both in an absolute framework and relative to manned aircraft incidents and accidents.

\section{References}

Academy of Model Aeronautics. (2016). An analysis of the FAA's March 2016 UAS sightings. Retrieved January 21, 2021, from http://amablog. modelaircraft.org/amagov/files/2016/06/AMA-Analysis-FINAL-6-116.pdf

Academy of Model Aeronautics. (2017). As drone sales soar, vast majority of reports remain simple sightings. Retrieved January 21, 2021, from https://www.modelaircraft.org/sites/default/files/ UASSightingsAnalysisbyAMA5-10-17.pdf

Aratani, L. (2019, January 24). Maybe the drone that snarled Newark airport operations wasn't a drone at all. Chicago Tribune. Retrieved January 21, 2021, from https://www.chicagotribune.com/business/ctbiz-newark-drone-could-be-balloon-space-junk-20190124-story.html

Britton, B., \& Clarke, H. (2018, December 24). Gatwick airport drones disruption wasn't all for nothing, UK police insist. Retrieved January 21, 2021, from https://www.cnn.com/2018/12/24/uk/gatwick-airportdrones-investigation-gbr-intl/index.html

Calder, S. (2019, January 22). Gatwick drone disruption cost over $£ 50 \mathrm{~m}$. The Independent. Retrieved January 21, 2021, from https://www. independent.co.uk/travel/news-and-advice/gatwick-drone-airport-costeasyjet-runway-security-passenger-cancellation-a8739841.html

Cardosi, K., Lu, J., France, M., Lennertz, T., Hoffman, A., \& Sheridan, T. (2018). Monitoring risk associated with operations of unmanned aircraft systems (UAS) in the national airspace system: Models for analysis of mandatory occurrence reports involving UAS-manned aircraft encounters (Report No. DOT-VNTSC-FAA-18-08). Report prepared for Federal Aviation Administration, Department of Transportation.

Cohen, J. (2019, January 22). Reported drone sightings cause flights to halt at Newark airport. Retrieved January 21, 2021, from https://www. nj.com/essex/2019/01/reported-drone-sightings-cause-flight-delays-atnewark-airport.html

D’Souza, K., Lyons, T., Lacy, T., \& Kota, K. R. (2017). Volume IV—UAS airborne collision severity evaluation-Engine ingestion. Federal Aviation Administration. Retrieved January 21, 2021, from https:// www.assureuas.org/projects/deliverables/a3/Volume\%20IV\%20-\% 20UAS\%20Airborne $\% 20$ Collision $\% 20$ Severity $\% 20$ Evaluation $\% 20-\%$ 20Engine\%20Ingestion.pdf

Debusmann, B. (2016, September 29). Drone at it again; Forces closure of Dubai airport. Khaleej Times. Retrieved January 21, 2021, from https:// 
www.khaleejtimes.com/nation/dubai/unauthorised-drone-causes-delayat-dubai-airport

Deulgaonkar, P. (2017, July 9). Shutting down Dubai international airport due to a drone costs $\$ 100,000$ a minute. Retrieved January 21, 2021, from https://www.arabianbusiness.com/content/375851-drone-costs100000-minute-loss-to-uae-airports

Dobush, G. (2019, February). Dubai airport disrupted by "unauthorized drone activity". Fortune. Retrieved January 21, 2021, from http:// fortune.com/2019/02/15/dubai-airport-disrupted-drone/

Dow, J. (2019, January 23). Here's what happens when drones get near airports. Retrieved January 21, 2021, from https://pix11.com/2019/01/ 23/heres-what-happens-when-drones-get-near-airports/

FAA investigating drone scare that grounded flights at Newark airport. (2019, January). Columbia Broadcasting System New York. Retrieved January 21, 2021, from https://newyork.cbslocal.com/2019/01/23/faainvestigating-newark-airport-drone-scare/

Federal Aviation Administration. (2006, March 24). Fact sheet-Colocated TRACONS (terminal radar approach control). Retrieved January 21, 2021, from https://www.faa.gov/news/fact_sheets/news_ story.cfm?contentkey $=4009$

Federal Aviation Administration. (2016). Law enforcement guidance for suspected unauthorized UAS operations. Retrieved October 20, 2021 from https://www.faa.gov/uas/resources/policy_library/media/FAA_ UAS-PO_LEA_Guidance.pdf

Federal Aviation Administration. (2018a). Integration of civil unmanned aircraft systems (UAS) in the national airspace system (NAS) roadmap. Retrieved January 21, 2021, from https://www.faa.gov/uas/resources/ policy_library/media/Second_Edition_Integration_of_Civil_UAS_ NAS_Roadmap_July\%202018.pdf

Federal Aviation Administration. (2018b). National plan of integrated airport systems (NPIAS) 2019-2023. Retrieved January 21, 2021, from https://www.faa.gov/airports/planning_capacity/npias/reports/media/ NPIAS-Report-2019-2023-Narrative.pdf

Federal Aviation Administration. (2020a). UAS sightings report. Retrieved January 21, 2021, from https://www.faa.gov/uas/resources/public _ records/uas_sightings_report/

Federal Aviation Administration. (2020b, September 9). Air traffic activity system (ATADS). Retrieved January 21, 2021, from https://aspmhelp. faa.gov/index.php/Aviation_Performance_Metrics_\%28APM\%29

Federal Aviation Administration. (2020c). Air traffic organization occurrence reporting (Order JO 7210.632A).

Federal Aviation Administration. (2020d). UAS data exchange (LAANC). Retrieved January 21, 2021, from https://www.faa.gov/uas/programs_ partnerships/data_exchange/

Gatwick airport: Drones ground flights. (2018, December). British Broadcasting Corporation. Retrieved January 21, 2021, from https:// www.bbc.com/news/uk-england-sussex-46623754

Gettinger, D., \& Michel, A. H. (2015). Drone sightings and close encounters: An analysis. Bard College, Center for the Study of the Drone. Retrieved January 21, 2021, from https://dronecenter.bard.edu/ files/2015/12/12-11-Drone-Sightings-and-Close-Encounters.pdf

Heinrich, H. W. (1941). Industrial accident prevention: A scientific approach. McGraw-Hill.

Kota, K. R., Ricks, T., Gomez, L., de los Monteros, J. E., Olivares, G., \& Lacy Jr, T. E. (2020). Development and validation of finite element impact models of high-density UAS components for use in air-to-air collision simulations. Mechanics of Advanced Materials and Structures, 27(13), 1178-1199. https://doi.org/10.1080/15376494.2020.1740956

Lyons, T., \& D'Souza, K. (2019). Parametric study of a unmanned aerial vehicle ingestion into a business jet size fan assembly model. Journal of Engineering for Gas Turbines and Power, 141(7). https://doi.org/10. $1115 / 1.4042286$

Mathew, J. K., Major, W. L., Hubbard, S. M., \& Bullock, D. M. (2017). Statistical modelling of runway incursion occurrences in the United States. Journal of Air Transport Management, 65, 54-62. https://doi. org/10.1016/j.jairtraman.2017.09.003
Mutzabaugh, B. (2015, January 23). Recreational drones ground Dubai flights Friday. USA Today. Retrieved January 21, 2021, from https:// www.usatoday.com/story/todayinthesky/2015/01/23/recreationaldrone-use-halts-flights-at-dubai-airport/22243995/

Nasseri, L. (2019, February 15). Dubai airport suspends flights after suspected drone activity. Bloomberg I Quint. Retrieved January 21, 2021, from https://www.bloombergquint.com/business/dubai-airportsconfirms-flights-suspension-over-suspected-drones\#gs.eFSyNqX5

Olivares, G., Gomez, L., de los Monteros, J., Baldridge, R., Zinzuwadia, C., \& Aldag, T. (2017b). Volume II-UAS airborne collision severity evaluation-Quadcopter. Retrieved October 20, 2021, from https:// www.assureuas.org/projects/completed/a3/Volume\%20II\%20-\% 20UAS\%20Airborne\%20Collision\%20Severity\%20Evaluation\%20-\% 20Quadcopter.pdf

Olivares, G., Lacy, T., Gomez, L., de los Monteros, J., Baldridge, R., Zinzuwadia, C., Aldag, T., Kota, K., Ricks, T., \& Jayakody, N. (2017a). Volume III-UAS airborne collision severity evaluation-Fixed-wing. Federal Aviation Administration. Retrieved October 20, 2021, from https://www.assureuas.org/projects/completed/a3/Volume\%20III\%20-\% 20UAS $\% 20$ Airborne $\% 20$ Collision $\% 20$ Severity $\% 20$ Evaluation $\% 20-\%$ 20Fixed-wing.pdf

Pennington, R. (2016, October 29). Dubai and Sharjah airports closed due to drone. The National. Retrieved January 21, 2021, from https://www. thenational.ae/uae/dubai-and-sharjah-airports-closed-due-to-drone-1. 160336

Porter, J. (2019, February 15). Dubai airport forced to halt departures due to drone sightings. Retrieved January 21, 2021, from https://www. theverge.com/2019/2/15/18226077/dubai-airport-drone-closureground-flights

Remeithi, N. A. (2016, June 11). Drone causes 69-minute closure at Dubai airport. Retrieved January 21, 2021, from https://www. thenational.ae/uae/transport/drone-causes-69-minute-closure-at-dubaiairport-1.227596

Shepardson, D. (2019, January 23). FAA details impact of drone sightings on Newark airport. Retrieved January 21, 2021, from https://www. reuters.com/article/us-usa-drones/faa-details-impact-of-dronesightings-on-newark-airport-idUSKCN1PH243

Silk, R. (2019, January 31). As drones proliferate, U.S. aviation in holding pattern. Travel Weekly. Retrieved January 21, 2021, from https://www. travelweekly.com/Travel-News/Airline-News/As-drones-proliferateaviation-in-holding-pattern

Topham, G. (2018, December 21). Two arrested as Gatwick reopens following latest drone sighting. The Guardian. Retrieved January 21, 2021, from https://www.theguardian.com/uk-news/2018/dec/21/ gatwick-airport-reopens-limited-number-of-flights-drone-disruption

Turner, A. (2021, January 4). 10 drones you can reach high altitudes with. Retrieved February 16, 2021, from https://www.dronesglobe.com/ guide/high-altitude/

United States Census Bureau. (2019). Annual estimates of the resident population for the United States, regions, states, and Puerto Rico: April 1, 2010 to July 1, 2019 (NST-EST2019-01). Retrieved January 21, 2021, from https://www.census.gov/data/tables/time-series/demo/ popest/2010s-state-total.html\#par_textimage_1574439295

Unmanned Aircraft Safety Team. (2017). Drone sightings analysis and recommendations. Retrieved January 21, 2021, from https://www. unmannedaircraftsafetyteam.org/wp-content/uploads/2018/01/UASTSightings-Executive-Summary-2017.pdf

Yeginsu, C. (2018, December 24). 1 broken drone, no video, 2 suspects released: Gatwick episode doesn't add up. The New York Times. Retrieved January 21, 2021, from https://www.nytimes.com/2018/12/ 24/world/europe/gatwick-airport-drone.html

Yu, J., Li, B., Liu, J., Hou, N., Zhang, Y., Wang, Y., \& Li, Y. (2021). Numerical simulation of a UAV impacting engine fan blades. Chinese Journal of Aeronautics, 34(10), 177-190. https://doi.org/10.1016/j.cja. 2020.10.025 